\begin{tabular}{|l|l|l|l|l|l|}
\hline MUNIBE Antropologia-Arkeologia & $n^{\circ} 66$ & $53-75$ & DONOSTIA & 2015 & ISSN 1132-2217 • eISSN 2172-4555 \\
\hline
\end{tabular}

\title{
El origen del Magdaleniense: una cuestión controvertida. La cueva de Las Caldas y los yacimientos del Nalón (Asturias, Norte de España)
}

\author{
The origin of the Magdalenian: a controversial issue. \\ Las Caldas cave and other sites in Nalón valley (Asturias, Northern Spain)
}

PALABRAS CLAVES: Región Cantábrica. Valle del Nalón. Cueva de Las Caldas. Solutrense. Badeguliense, Origen del Magdaleniense. GAKO-HITZAK: Kantaurialdea. Nalón harana. Las Caldaseko kobazuloa. Solutre aldia. Badegulian aldia, Madeleine aldiaren jatorria.

KEY WORDS: Cantabrian region, Nalon Valley, Las Caldas Cave, Final Solutrean, Badegulian, Magdalenian origen.

\section{Ma Soledad CORCHÓN RODRÍGUEZ(1), Paula ORTEGA MARTíNEZ(1) \& Francisco J. VICENTE SANTOS ${ }^{(2)}$}

\section{RESUMEN}

La transición entre el Solutrense y Magdaleniense es una cuestión ampliamente discutida tanto en los territorios franceses como peninsulares. Ante la dificultad de determinar la continuidad o discontinuidad entre ambas culturas, y sobre todo la identificación y caracterización del Badeguliense en Francia, se ha creado un crisol de teorías sobre el final del Solutrense y el origen del Magdaleniense peninsular. La caracterización de este posible nuevo horizonte, que se pretende introducir en algunas estratigrafías de yacimientos modernamente excavados con un claro cariz rupturista, introduce alguna confusión a la hora de determinar un contexto paleoclimático y cronológico preciso para estas industrias. La adscripción de niveles del final del Solutrense (Caldas XIV y 3-6; La Riera 9-14), y también del Magdaleniense inferior clásico (Caldas XIII), a un Badeguliense cantábrico, Solutrense Final, Magdaleniense arcaico o Magdaleniense inferior no es una cuestión menor ni terminológica. Por el contrario, la identificación de uno u otro horizonte sigue estando sujeta a comparaciones cronológicas, al estudio de niveles aislados o a la identificación de elementos líticos y óseos aislados del registro arqueológico, que no siempre están presentes en su totalidad (raclettes, materias primas locales, técnicas no laminares y técnica pseudo-excisa).

Este trabajo se centra en el estudio de los depósitos del final del Solutrense y su relación con los más antiguos niveles magdalenienses, en el contexto estratigráfico del valle del Nalón (La Paloma, Entrefoces, y Las Caldas). Se presta especial atención a la amplia secuencia de la cueva de Las Caldas (niveles XI a XIII, XIV y 3 a 6), en la que se suceden las ocupaciones del Solutrense final y el Magdaleniense inferior en las salas I y |l de la cavidad, y para cuya datación se dispone de 26 dataciones ${ }^{14} \mathrm{C}$ (AMS y ${ }^{14} \mathrm{C}$ convencional).

\section{LABURPENA}

Solutre eta Madeleine aldien arteko trantsizioa Frantzian zein penintsulan askotan eztabaidatu izan den gaia da. Bi kultura horien artean jarraipena edo etenaldia gertatu zen zehaztea zaila denez eta, batez ere, Frantzian Badegulien aldia identifikatzea eta bereiztea zaila denez, Solutre aldiaren amaieraren eta penintsulako Madeleine aldiaren jatorriaren arteko teoria ugari sortu da. Aurrekoa hausteko helburu argiarekin modu modernoan induskatutako aztarnategien estratigrafia batzuetan txertatu nahi den aukera berri posible horren karakterizazioak nolabaiteko nahasketa gehitu du industria horietarako testuinguru paleoklimatiko eta kronologiko zehatza finkatzeko garaian. Solutre aldiaren amaierako mailak (Caldas XIV eta 3-6; La Riera 9-14) eta beheko Madeleine aldi klasikokoak (Caldas XIII) Kantaurialdeko Badegulien aldira, Amaierako Solutre aldira, Madeleine aldi arkaikora edo beheko Madeleine aldira atxikitzea ez da garrantzi gutxiagoko gaia edo terminologiari lotuta bakarrik dagoena. Aldiz, aukera bat edo bestea identifikatzea oraindik ere honako hauen mende dago: alderaketa kronologikoak, isolatutako mailen ikerketa edo erregistro arkeologikoko lisis- edo hezur-elementu isolatuen identifikazioa, eta horiek ez dira osorik presente egoten beti (racletteak, tokiko lehengaiak, teknika ez-laminarrak eta teknika pseudo-eszisoa).

Lan hau Solutre aldiaren amaierako metakinen ikerketan eta Madeleine aldiko maila zaharrenekin duten loturan oinarritu da, Nalon haraneko testuinguru estratigrafikoan (La Paloma, Entrefoces eta Las Caldas). Arreta berezia jarri da Las Caldaseko kobako sekuentzia zabalean (XI.etik XIII.era arteko mailak, XIV.a, eta 3tik Gra arteakoa). Horietan, amaierako Solutre aldiko eta beheko Madeleine aldiko okupazioak daude barrunbeko I. eta II. aretoetan. Horien datak zehazteko, $26{ }^{14} \mathrm{C}$ datazio daude (AMS eta ${ }^{14} \mathrm{C}$ konbentzionala).

\section{ABSTRACT}

The transition between the Solutrean and Magdalenian is widely discussed question both in the French territories like peninsular sites. Given the difficulty of determining the continuity or discontinuity between the two cultures; and especially the characterization of Badegulian in France, a melting pot of theories about Final Solutrean and the origin of peninsular Magdalenian have been postulated. The characterization of this possible new horizon embedded in the stratigraphy of recently excavations sites with a clear complexion breakaway, create more confusion in order to establish a paleoclimatic and chronological context. The assignment of Final Solutrean (Caldas XIV and 3-6; La Riera 9-14,...) and Early Magdalenian levels (Caldas XIII)

\footnotetext{
(1) Universidad de Salamanca. Depto. de Prehistoria Historia Antigua y Arqueología. C/Cervantes s/n 37002 Salamanca scorchon@usal.es; ortegap@usal.es

(2) Museo de Salamanca. Patio de Escuelas Mayores s/n, 37002 Salamanca. fjvsantos@usal.es
} 
to a Cantabrian Badeguliense, Final Solutrean or archaic Magdalenian is not a trivial matter, nor purely terminological. On the contrary the identification is subjected to chronological comparisons, the isolate level analysis, or the identification of specific lithic or bone records that are not all of them always present (raclette, local raw materials, non-lamellar techniques, and technical pseudo-excisa ).

In this context, this study is focused on the analysis of the end of the Solutrean deposits, and its relationship with the Early Magdalenian levels in the stratigraphic context of Nalon Valley (La Paloma, Entrefoces, and Las Caldas). Special attention is given to the extensive sequence of Las Caldas (XI XIII , XIV and 3-6 ) where Solutrean and Magdalenian levels are succeed in the Sala I and II, and which has 26 dating ${ }^{14} \mathrm{C}$ AMS and ${ }^{14} \mathrm{C}$ ordinary.

\section{1.- INTRODUCCION. ESTADO DE LA CUESTION}

El origen del Magdaleniense en la Cornisa cantábrica, su relación con los últimos niveles solutrenses y la aparente discontinuidad entre ambas secuencias es una cuestión controvertida. En particular, centran los debates actuales las relaciones tecno-tipológicas entre el final del Solutrense y algunos niveles que le suceden en los mismos yacimientos en la Península ibérica (ÁLVAREZ y ARRIZABALAGA, 2012), así como las dataciones que pudieran relacionar cronológicamente estos últimos con el Badeguliense francés. Sin embargo, se echa en falta una visión regional actualizada que arroje alguna luz en el debate sobre las conexiones existentes entre los niveles y yacimientos de las regiones del centro y suroeste de Francia ca. 20,000-18,000 BP con otros de la Península Ibérica, que un sector de la investigación tiende a relacionar (SAUVET et al., 2008; AURA et al., 2012) obviando que se trata de territorios desconectados geográficamente. Además, no se han documentado relaciones culturales, intercambios de materias primas, difusión de tecnologías o introducción de nuevos productos manufacturados entre aquellas regiones y el Norte de España, como sucede al avanzar el Magdaleniense cantábrico respecto del mismo horizonte en los Pirineos franceses.

En la Cornisa cantábrica, la discusión se focaliza en torno a la existencia de una posible intrusión de nuevas tecnologías de talla y de procesado del material óseo, que fracturarían la continuidad entre los niveles del Solutrense superior regional y los que culminan la secuencia a finales del Solutrense, así como sus relaciones con el Magdaleniense inicial. Más discutibles son los ensayos de reubicación estratigráfica de algunos niveles modernamente excavados en Asturias (BOSSELIN y DJINDJIAN, 1999; BOSSELIN, 2000), como es el caso de las extensas secuencias solutrenses y magdalenienses de La Riera (STRAUS 2000) y Las Caldas (CORCHÓN, 1994 y 1999), o en curso de excavación como El Mirón en Cantabria, donde tampoco se encuentran vestigios badegulienses (STRAUS et al., 2014), sustentada en elementos tipológicos escasos y poco significativos. Este debate, que atañe tanto a diversas secuencias solutrenses en Asturias, Cantabria y una estación del País Vasco (Aitzbitarte IV), como a otros yacimientos del arco mediterráneo ibérico (Parpa-
Iló, el Volcán del Faro, Gato II, en: AURA, 2007; VADILLO, 2012, UTRILLA et al., 2012), hasta la fecha plantea más interrogantes que soluciones.

En cuanto a la cuestión de si existe o no Badeguliense francés al sur de los Pirineos, es igualmente recurrente en la historiografía sobre el origen del Magdaleniense desde los años ochenta (UTRILLA, 1985). Arranca de las primeras propuestas de sistematización de los niveles "protomagdalenienses" de Badegoule y Abri Lachaud (CHEYNIER, 1939 y 1949), siendo utilizada esta denominación por primera vez para las nuevas industrias de Les Ronces en Gros Monts de Nemour (VACHER y VIGNARD, 1964; VIGNARD, 1965). Estos y otros conjuntos líticos y óseos regionales, especialmente los del Abri Fritsch, presentaban abundantes raclettes y buriles sobre gruesas lascas transversales y escotaduras, además de perforadores múltiples y matrices en asta de cérvido de factura arcaica, troceadas por percusión y no mediante ranurado. Estas industrias sobre lascas y sin hojitas de dorso, se consideraron transicionales entre el Solutrense y el Magdaleniense, lo que permitía matizar los planteamientos iniciales de Cheynier, que ya había sugerido que esta secuencia correspondería a un horizonte cultural independiente del Solutrense (ALAIN y FRITSCH, 1967).

A partir de la revisión de los materiales recuperados en las excavaciones de los yacimientos clásicos, particularmente de los abrigos de Cuzoul en Lot (1982-1986) y Fritsch en Indre (1957-1963 y ss.) (ALAIN y FRITSCH, 1967; TROTIGNON et al., 1984), además de otros en Dordoña (Laugerie-Haute-Este) y Lot-et-Garonne (Cassegros), las características de estas industrias adquieren una complejidad y diversidad crecientes. La sistematización de los conjuntos, aplicando criterios tecnológicos, permite concluir que se trata de unos procesos técnicos de talla con baja estandarización, lo que se traduce en una producción masiva de lascas en detrimento de las hojas, y la consecuente caída de los índices de laminaridad (DUCASSE y LANGLAIS, 2007; LANGLAIS et al., 2013; DUCASSE, 2012 y 2013). Esta aparente diversificación de los procesos de talla respecto del Solutrense, que es el resultado de la aplicación de otro tipo de cadenas operativas líticas, se interpreta como una adaptación a las rigurosas condiciones climáticas del Último Máximo Glaciar, con modos de producción más efectivos (DUCASSE y LANGLAIS, 2007)¹. Por

\footnotetext{
1 Se plantean distintas interpretaciones para explicar la evolución de las secuencias estratigráficas en el SW de Francia y la cuenca parisina. Para estas regiones se postula una interpretación secuencial, en la cual el final del Solutrense superior es cubierto estratigráficamente por Badeguliense antiguo, reciente y final, derivando ulteriormente hacia un Magdaleniense inferior (ALLAIN, 1989; DUCASSE y LANGLAIS, 2007; RÍOS et al., 2008). Los últimos estudios realizados en los yacimientos franceses plantean el envejecimiento de las dataciones del Badeguliense hasta 23,5 ka calBP (cf. nota 2), lo que implica su solapamiento con las cronologías establecidas para el Solutrense superior, y plantea nuevos interrogantes acerca de este horizonte cultural en los territorios franceses (DUCASSE et al., 2013).
} 
otra parte, la variabilidad que muestran estos registros líticos conduce a la definición de facies o modelos en el interior del Badeguliense. Pero esta perspectiva de análisis oscurece la interpretación de las industrias, particularmente fuera del ámbito de Dordoña, Quercy y el centro de Francia, al postular la existencia de niveles badegulienses de facies con raclettes y niveles badeguliense de facies con triángulos. Y paralelamente, abre nuevos interrogantes acerca de las relaciones entre estas modalidades de Badeguliense y el Magdaleniense inferior que le sucede, sobre las cuales hasta la fecha no existe consenso entre los investigadores. En suma, los interrogantes que plantea el modelo de una difusión y penetración de nuevas gentes, o bien los postulados que interpretan el Badeguliense como un proceso de adaptación al LGM basado en una evolución tecnológica, son cuestiones aún oscuras que no aclaran las naturaleza tecno-tipológica del Badeguliense, y qué entidad estratigráfica tiene fuera de aquellos territorios.

Finalmente, según los últimos datos disponibles (DUCASE et al., 2012, 2014), la extensión de la secuencia estratigráfica y sus facies más allá de los Pirineos contrasta con la reducción de la amplitud temporal del conjunto de las ocupaciones badegulienses, y con el envejecimiento de la horquilla temporal atribuida a las mismas en la extensa secuencia de Cuzoul (23,5 - 22,2 ka calBP)2. Estos aspectos desdibujan tanto la división interna del Badeguliense francés como su relación con el Solutrense superior. Y los nuevos datos contrastan también con los modelos que postulan un gran desbordamiento espacial del Badeguliense, desde sus núcleos originarios en Francia hacia los espacios atlántico, cantábrico y mediterráneo de la península Ibérica.

Centrándonos en la Cornisa cantábrica, el debate acerca de la relación entre los últimos niveles solutrenses y los primeros magdalenienses, en la actualidad adolece de un importante vacío de información y plantea nuevos interrogantes. Por un lado, la ausencia de estudios diacrónicos que relacionen las secuencias de los grandes yacimientos de la región, habitados entre ca. 21,000 BP y 14,000 BP, imposibilitan decantarse por un modelo de sustitución del Solutrense cantábrico, que representa un brillante y dilatado proceso tecnológico desarrollado a nivel local, que sería interrumpido por una "intrusión" de tradiciones y prácticas tecnológicas distintas. O bien por un modelo diferente que muestra cómo se produce en los niveles solutrenses un proceso de cambio gradual, a nivel tecnológico y tipológico, iniciado antes del Solutrense superior y que afecta también a la gestión de las materias primas y la captación de otros recursos económicos del entorno. Este proceso se habría realizado in situ, en los mismos territorios.

Y por otra parte, la utilización de la escasa información rigurosa que es posible extraer de las excavaciones antiguas, así como las interpretaciones tecno-tipológicas que se sustentan en niveles aislados, sin la perspectiva de un contexto temporal dilatado, están incrementando la confusión que rodea este debate.

En algunos yacimientos, los datos son insuficientes a causa del vacío de información que generan la existencia de hiatus y discordancias erosivas, habituales en los registros solutrenses y magdalenienses dadas las características de las cavidades cársticas de la Cornisa Cantábrica, que producen rupturas en las secuencias estratigráficas. Sirven de ejemplo en el valle del Nalón las estratigrafías del Abrigo de la Viña y la cueva de Las Caldas para el Solutrense superior y los inicios del Magdaleniense. En el Abrigo de La Viña una importante discordancia erosiva separa el nivel V (Solutrense superior) del IV (Magdaleniense medio), fosilizando éste un paleo-relieve que ocupa el techo del V (Hoyos, en FORTEA et al., 1990: 223). En el caso de Las Caldas, el Solutrense superior final de la sala II se presenta en discordancia erosiva respecto de la primera ocupación del Magdaleniense inicial, ofreciendo las dataciones un intervalo temporal superior a 2500 años (nivel XIV: 20478 21195; nivel XIII: 18051 - 18597, 2 $\sigma$ calBP), que es menester valorar. Y en la sala I, más cercana a la boca de la cueva, los importantes procesos de inundación que se producen en los episodios húmedos afectaron a los depósitos del Solutrense superior y final, y aquí no se han conservado depósitos del Magdaleniense inferior, evacuados al exterior por la boca de Caldas I, siendo desigual la conservación de los niveles en las distintas zonas de la sala.

Precisamente por estas limitaciones del registro estratigráfico, parece una tarea urgente analizar con detalle las tendencias a largo plazo, las innovaciones técnicas y morfológicas que se van generalizando en los utillajes, y avanzar posibles explicaciones a los cambios tecno-tipológicos y su reflejo en los sucesivos niveles, es decir, a la adopción permanente de los nuevos artefactos y modos de talla. En cambio, insertar a fortiori entre dos paquetes estratigráficos un horizonte nuevo badeguliense, o bien subsumir el techo Solutrense y la base del Magdaleniense en un solo registro, no aporta nueva información sino que introduce una mayor confusión en la cuestión del origen del Magdaleniense cantábrico. En cuanto al Badeguliense francés, los datos actuales no permiten definirlo con claridad. Y en su caso: ¿qué modalidad de Badeguliense habría alcanzado los territorios cantábricos, evitando mayoritariamente las regiones orientales más cercanas al entorno pirenaico?

\section{2.- EL FINAL DEL SOLUTRENSE EN EL VALLE DEL NALÓN}

El valle del Nalón constituye la frontera natural que marca el límite occidental de los relieves cársticos, y en consecuencia del grueso de los asentamientos en cavidades o abrigos, ya que no se conocen por el momento asentamientos al aire libre. En cuanto a los yacimientos

\footnotetext{
${ }^{2}$ En Cuzoul, en contraste con la dilatada secuencia tradicional $\left({ }^{14} \mathrm{C}\right.$ ordinario: $24-19$ calBP), las nuevas dataciones ${ }^{14} \mathrm{C}(\mathrm{SMA})$ envejecen y reducen este marco: Badeguliense antiguo (c.27), $19150 \pm 110$ BP; Badeguliense reciente (c.6), $18620 \pm 100$ BP (23447-22757 a 22757-22290, $2 \sigma$ calBP), lo que imposibilita distinguir el Solutrense superior del Badeguliense antiguo (DUCASSE et al., 2014: 40-43).
} 
existentes en el curso medio y bajo del río, ofrecen algunas diferencias respecto de lo que acontece en el mismo periodo en el centro y oriente cantábricos. Por otra parte, mientras que en el Nalón y su red de valles tributarios no abundan las ocupaciones del Magdaleniense inferior -La Paloma, Las Caldas, Entrefoces, y algunos indicios conservados en el Covacho de Candamo-, los yacimientos y registros estratigráficos del Solutrense son de una amplitud desconocida en los territorios vecinos. Se trata de unos asentamientos con una cultura material brillante y dilatada en el tiempo (ca. 24000 a 20500 cal BP), a los que se viene asociando tradicionalmente una parte importante del arte parietal del Nalón, con una quincena de sitios con grabados en el exterior de las cuevas o abrigos y pinturas en el interior de cavidades (CORCHÓN, 2015) (Fig.1).

Al respecto, la cueva de Las Caldas, y en concreto la parte superior de la Galería o Caldas I que es la zona donde se encuentran el yacimiento y los grabados exteriores, puede arrojar alguna luz sobre estas cuestiones. Se trata de un yacimiento que conserva una amplia secuencia estratigráfica representativa de las ocupaciones humanas del valle del Nalón, con una secuencia de niveles del periodo estudiado, Solutrense superior final-Magdaleniense inferior (ca. 20,500 - 16,500 calBP). Reviste un gran interés analizar los datos proporcionados por estos niveles, ya que permiten conocer el cambio tecnológico y cultural que se produce a finales del Solutrense, respecto del Solutrense superior clásico subyacente, y sus diferencias con el Magdaleniense inferior cantábrico que le sucede en la ocupación de la cavidad.

\subsection{La secuencia de Las Caldas}

El yacimiento de Las Caldas I ha sido excavado en una superficie de $25 \mathrm{~m}^{2}$, distribuidos entre el vestíbulo, el PasiIlo y las salas I y II. El paquete estratigráfico solutrense más potente corresponde a la Sala I, donde alcanza 2,60 m. de potencia, con 17 niveles que abarcan la secuencia completa del Solutrense cantábrico (19-Base a 3). De ellos, nos interesan aquí las ocupaciones correspondientes al Solutrense superior final (niveles 5 a 3; en adelante: Solutrense final). Sobre esta serie, se encuentran restos de otros dos niveles magdalenienses erosionados (2A y $2 B$ ). A su vez, las excavaciones realizadas en la Sala II comprenden una extensión de $7 \mathrm{~m}^{2}$, y son representativos de las diversas ocupaciones dadas las reducidas dimensiones de la misma (7 × 4 m.). En esta salita, situada al final del espacio habitado, únicamente se ha conservado un nivel Solutrense final (XIV) reposando sobre el piso calizo natural, ya que los niveles solutrenses más antiguos -que debieron existir an-

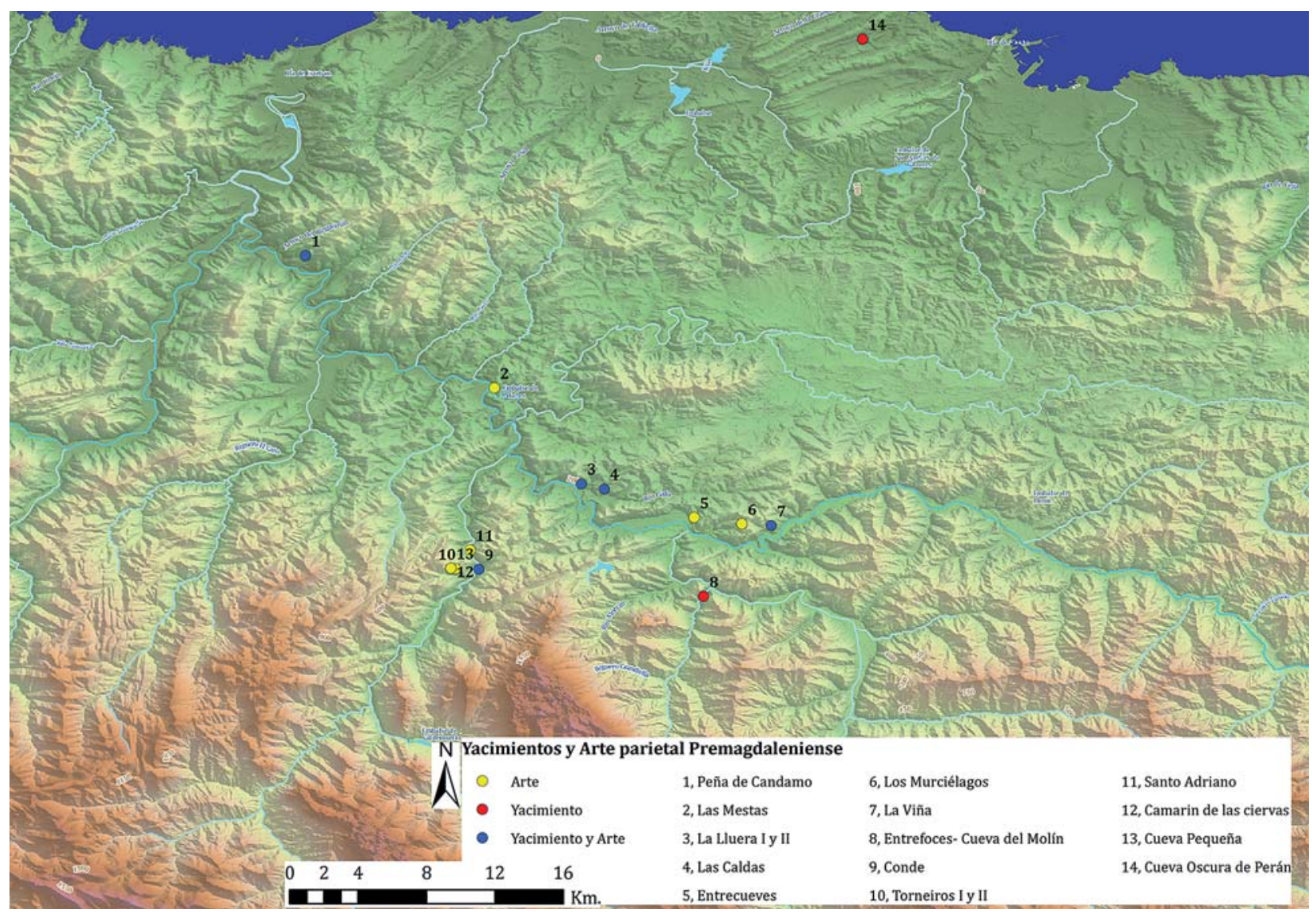

Fig. 1. Distribución de los yacimientos y sitios con arte rupestre pre-magdaleniense del valle del Nalón. / Layout of the sites and locations with Pre-Magdalenian cave art in the Nalon Valley. 
teriormente dada la geometría de los depósitos-, fueron evacuados hacia Caldas II por dos gateras existentes en el lado derecho, en sucesivas crecidas del rio hipogeo que circula por la galería inferior. Sobre el nivel XIV se sedimentó un potente relleno de 16 niveles magdalenienses, que comprende todos los estadios de la secuencia: Magdaleniense inferior, medio (antiguo y reciente), superior y final. Este depósito magdaleniense corresponde a un estadio paleo-climático de características frías (GS 2c), previo a la Oscilación de Lascaux, y se extiende hasta el Alleröd (Gl 1e-c) según los datos disponibles.

En conjunto, la secuencia estratigráfica de Las Caldas I abarca una horquilla temporal de unos 10.000 años, de acuerdo con la serie de 26 dataciones ${ }^{14} \mathrm{C}$ (CORCHÓN, 2009) obtenidas en ambas salas y el Pasillo I (Tabla 1). Abarca desde los inicios del Solutrense regional (Solutrense medio de la secuencia occidental), uno de cuyos niveles ha sido fechado en $24185 \pm 370$ calBP (niv.15), aunque no es el más antiguo, hasta el Magdaleniense superior (datado en el nivel I en $14936 \pm 342$ calBP. Para el nivel más reciente (2A, Magdaleniense final de la Sala I), deficientemente conservado por erosión, no se dispone de dataciones.

El paquete estratigráfico que ocupa la base de la estratigrafía de la Sala II, estudiado en este trabajo, conserva una industria típica del final del Solutrense subyaciendo a los niveles del Magdaleniense inferior. El hecho de que este tramo se presente sedimentológicamente aislado e individualizado de otras ocupaciones anteriores (Solutrense superior) y posteriores (Magdaleniense medio) existentes en la cueva, excluye la posibilidad de contaminaciones o mezclas de materiales con dichas secuencias. Comprende desde la base de la estratigrafía (nivel XIV) hasta el techo del nivel XI, apareciendo éste se-

\begin{tabular}{|c|c|c|c|c|}
\hline Ref. Lab. & $14 \mathrm{C} B P$ & $\begin{array}{c}\text { CalBP_CalPal 2007-HULU } \\
\text { (68\% range calBP) }\end{array}$ & Nivel / Sector & Clasificación \\
\hline Ua-15318 & $20250 \pm 235($ AMS $)$ & $24185 \pm 370(23814-24555)$ & 15 (Sala I) & Solutrense Medio \\
\hline Ly-2428 & $19510 \pm 330$ & $23340 \pm 468(22872-23808)$ & 16 (Topera) & Solutrense Medio \\
\hline Ly-2426 & $19480 \pm 260$ & $23296 \pm 413(22882-23709)$ & 12b (Pasillo) & Solutrense Medio \\
\hline Ly-2425 & $19030 \pm 320$ & $22857 \pm 404(22452-23261)$ & 12t (Pasillo) & Solutrense Medio \\
\hline Ly-2429 & $19000 \pm 280$ & $22843 \pm 379(22464-23222)$ & 18 (Topera) & Solutrense Medio \\
\hline Ly-2424 & $19390 \pm 260$ & $23199 \pm 398(22801-23597)$ & 9 (Pasillo) & Solutrense Superior \\
\hline Ly-2423 & $18310 \pm 260$ & $21960 \pm 388(21571-22348)$ & 7 (Pasillo) & Solutrense Superior \\
\hline Ua-15316 & $18305 \pm 295$ (AMS) & $21949 \pm 412(21537-22361)$ & 11 (Sala I) & Solutrense Superior \\
\hline Ua-15315 & $17945 \pm 370($ AMS $)$ & $21541 \pm 603(20938-22144)$ & 9 (Sala I) & Solutrense Superior \\
\hline Ua-4302 & $17380 \pm 215(\mathrm{AMS})$ & $20837 \pm 358(20478-21195)$ & XIVc (Sala II) & Solutrense Final \\
\hline Ly-2422 & $17050 \pm 290$ & $20405 \pm 495(19910-20900)$ & 4 (Pasillo) & Solutrense Final \\
\hline Ly-2421 & $18250 \pm 300$ & $21904 \pm 424(21480-22328)$ & 3 (Pasillo) & Solutrense Final \\
\hline Ua-4301 & $15165 \pm 160$ (AMS) & $18324 \pm 273(18051-18597)$ & XIII (Sala II) & Magdaleniense inferior \\
\hline Ua-4300 & $14835 \pm 130(\mathrm{AMS})$ & $18156 \pm 282(17874-18438)$ & XII inf (Sala II) & Magdaleniense inferior \\
\hline Ua-2735 & $14495 \pm 140$ (AMS) & $17635 \pm 282(17353-17917)$ & XII (Sala II) & Magdaleniense inferior \\
\hline Ua-2734 & $13755 \pm 120$ (AMS) & $16881 \pm 230(16651-17111)$ & XI (Sala II) & Magdaleniense inferior \\
\hline Ua-10188 & $13370 \pm 110(\mathrm{AMS})$ & $16297 \pm 436(15860-16733)$ & IX (Sala II) & Magdaleniense Medio \\
\hline Ua-10189 & $13640 \pm 150(\mathrm{AMS})$ & $16604 \pm 393(16211-16997)$ & VIII (Sala II) & Magdaleniense Medio \\
\hline Ly-2936 & $13310 \pm 200$ & $16220 \pm 475(15745-16695)$ & VIII (Sala II) & Magdaleniense Medio \\
\hline Ly-3318 & $12869 \pm 160$ & $15571 \pm 512(15059-16083)$ & VII (Sala II) & Magdaleniense Medio \\
\hline Ua-10190 & $13650 \pm 140$ (AMS) & $16641 \pm 363(16277-17004)$ & VIc (Sala II) & Magdaleniense Medio \\
\hline Ly-2427 & $13400 \pm 150$ & $16314 \pm 454(15860-16768)$ & IV/III (Sala II) & Magdaleniense Medio \\
\hline Ua-10191 & $13185 \pm 155$ (AMS) & $16114 \pm 441(15672-16555)$ & IIIb-IIIc (Sala II) & Magd. Medio / Superior \\
\hline Ua-10192 & $12960 \pm 190($ AMS $)$ & $15775 \pm 529(15245-16304)$ & II (Sala II) & Magdaleniense Superior \\
\hline Ua-10193 & $12595 \pm 125($ AMSA $)$ & $14936 \pm 342(14594-15278)$ & I (Sala II) & Magdaleniense Superior \\
\hline Ua-10194 & $12590 \pm 120$ (AMS) & $14931 \pm 337(14593-15268)$ & -II (Sala II) & Magdaleniense Superior \\
\hline
\end{tabular}

Tabla 1: Dataciones de los niveles de cueva de Las Caldas (primeras excavaciones: ${ }^{14} \mathrm{C}$ ordinario; excavaciones recientes: ${ }^{14} \mathrm{C}$ AMS). CalPal-Hulú 2007 (revisado 2015). / Dating of the Las Caldas cave levels (first digs: Standard C14; recent digs:14C AMS). CalPal-Hulú 2007 (reviewed 2015). 
llado por un grueso paquete de limos estériles de inundación de $40 \mathrm{~cm}$. de espesor (nivel X), que separan el Magdaleniense inferior del medio y superior.

El nivel XIV alcanza un espesor máximo de $30 \mathrm{~cm}$, y sobre él se encuentra un depósito de cuatro niveles del Magdaleniense inferior, cuya potencia oscila entre los 133 y $65 \mathrm{~cm}$ : los niveles XIII (22 a $9 \mathrm{~cm}$ de espesor máximo y mínimo), XII-inf. (20 a $9 \mathrm{~cm})$, XII (64 a $34 \mathrm{~cm}$ ) y XI (12,5 a $27 \mathrm{~cm}$ ). Este último conserva en el techo un hogar construido con grandes bloques, bien conservado y con abundante material, sellado a techo por los citados limos de inundación (Fig.2).

En primer lugar, hay que señalar que todos los niveles del Solutrense final de Las Caldas I (niveles 3 a 5 de la Sala I, y XIV de la Sala II), presentan una gran homogeneidad entre sí, y sus características son comparables a las de otros niveles coetáneos de la Cornisa cantábrica, como Riera 9-14 (STRAUS, 1986; BOSSELIN y DJINDJIAN, 1999), Chufín 1 (CABRERA, 1977; CABRERA et al., 1976) y Amalda IV (ALTUNA, 1990). Se han denominado Solutrense final por su posición estratigráfica culminando aquella secuencia, pero todos ellos -al igual que los citados anteriormente en los territorios vecinos-, ofrecen una notoria continuidad con los niveles subyacentes, Solutrense superior sensu stricto, y si bien se percibe un descenso en el número de los foliáceos, éstos son tecnológica y tipológicamente similares (Fig.3). Y en la secuencia más extensa de Las Caldas (Sala I), esta continuidad también es estratigráfica superponiéndose al Solutrense superior (niveles 12 a 6) sin rupturas sedimentarias, y sin que percibamos un brusco cambio en la explotación de las materias primas o una intrusión de elementos foráneos que interrumpa un proceso tecnológico iniciado anteriormente.

Esporádicamente, en estos niveles se encuentran algunas raclettes, siempre con un número muy discreto de ejemplares, cuya significación diagnóstica ha sido sobrevalorada. El resto de los elementos tipológicos considerados representativos de los niveles badegulienses, como son los buriles transversales, en Las Caldas son muy raros o están ausentes, como sucede con las astas fracturadas por percusión y no por ranurado. Por el contrario, en estos niveles se encuentran otros elementos que no se encuentran en el Badeguliense francés, como las hojitas de dorso y Dufour-representadas por una treintena de piezas en
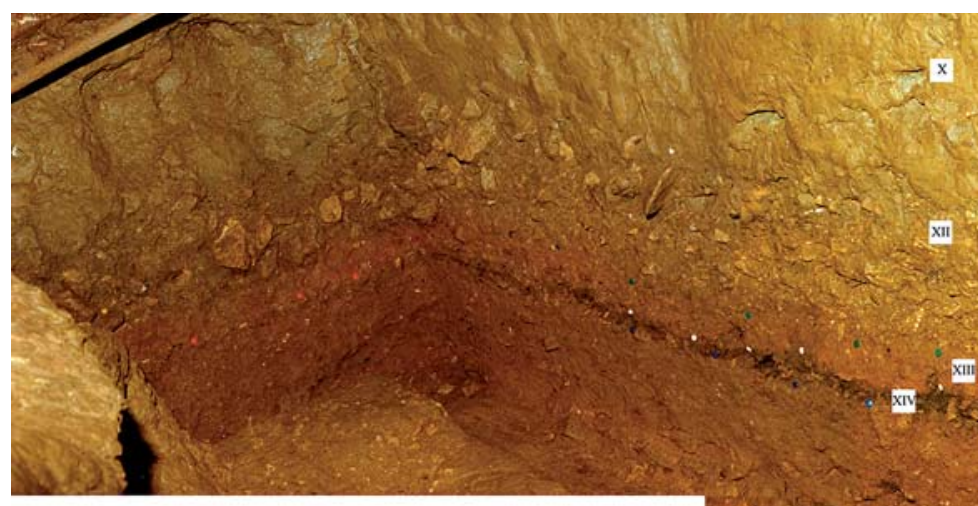
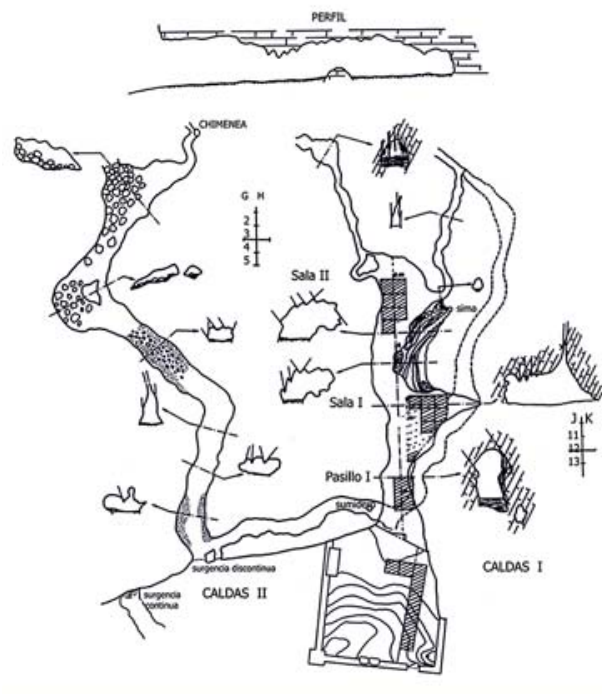

Fig. 2. Karst de Las Caldas y estratigrafía de la Sala II. Detalle del corte erosivo afectando a los niveles XIV-XIlinf. / Las Caldas karst and the stratigraphy of Room II. Details of the erosion line affecting levels XIV-XIlinf. 


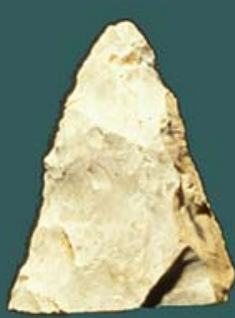

1126

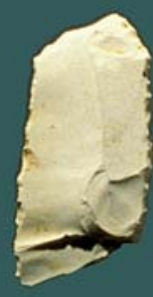

9425

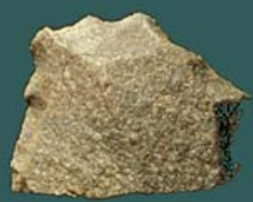

1142

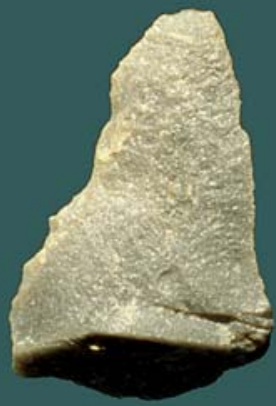

1304

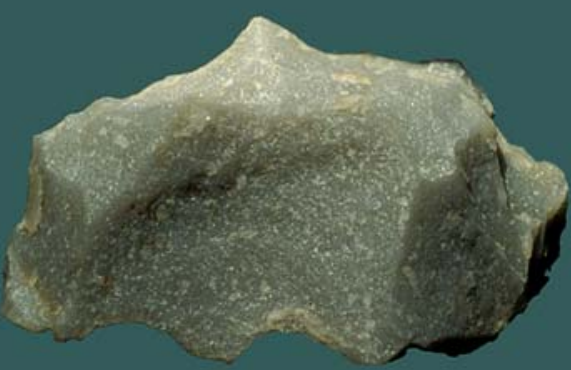

1373

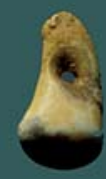

1154

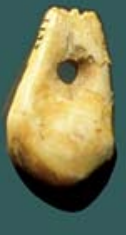

1149
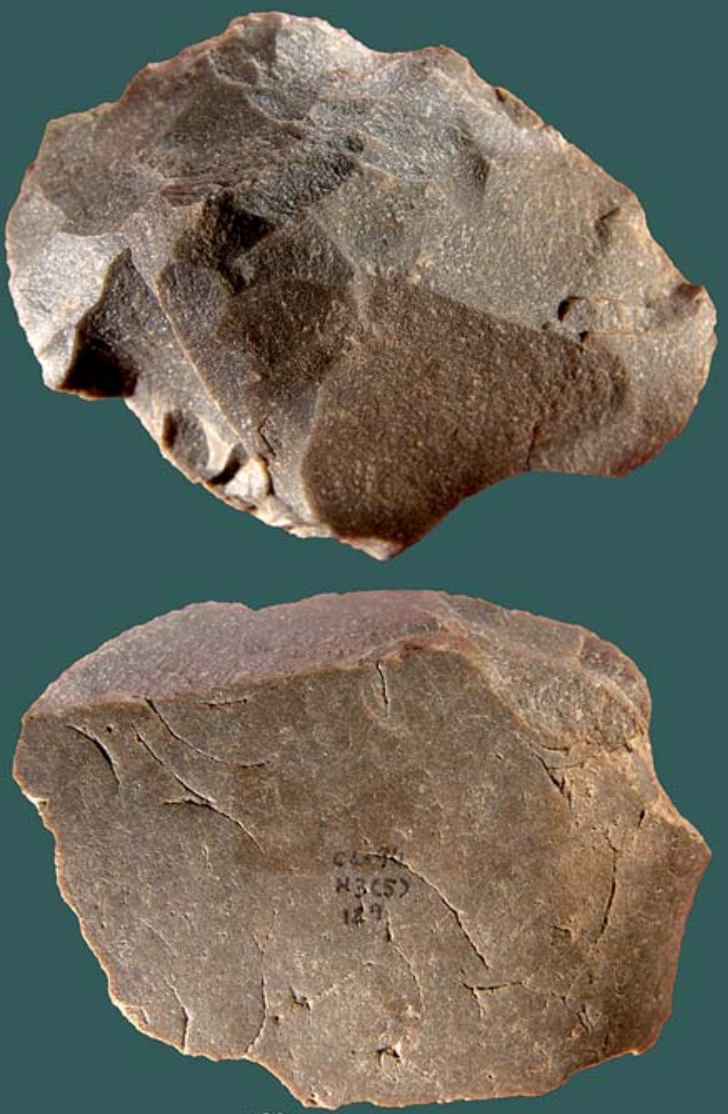

129

0

$50 \mathrm{~mm}$

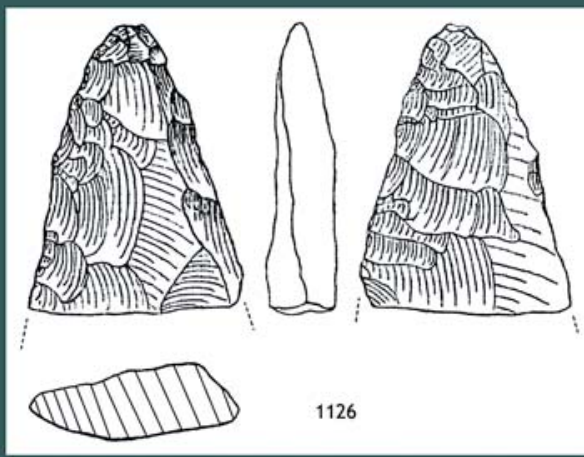

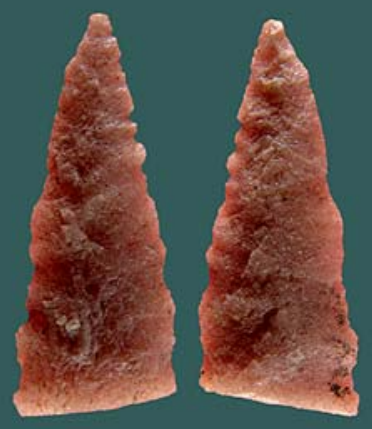

2220

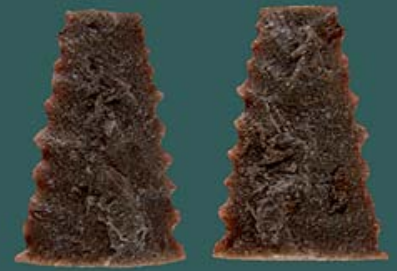

2223

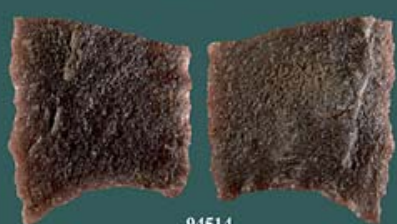

94514

Fig. 3. Las Caldas, Sala II, nivel XIV. Sílex: hoja de laurel y hoja retocada (local y Piloña: 1126, 9425). Cuarcita: hojas de laurel (1126, 2220, 2223, 94514), raspador (1142), escotadura inversa (1304), perforador (1373) y núcleo-rabot (129). Colgantes: canino izquierdo de ciervo hembra y macho (1154 y 1149). I Las Caldas, Room II, level XIV. Flint: laurel leaf and retouched blade (local and Pilona: 1126, 9425). Quartzite: laurel leaves (1126, 2220, 2223, 94514), scraper (1142), inverse notch (1304), piercer (1373), and core-rabot (129). Pendants: left canine of a female and male deer (1154 and 1149). 
Ios niveles 3 a 5 de la Sala I, y una decena en el XIV de la Sala II, o el triángulo (n. XIV). Y también se encuentra en estos niveles una amplia representación de azagayas circulares u ovales, monobiseladas o con doble aplastamiento basal estriado, así como el tipo de varilla cuadrangular y la aguja.

En suma, el final del Solutrense de Las Caldas, fechado en la Sala II entre $20478-21195$ cal BP $2 \sigma$ (niv. XIVc, AMS: $17380 \pm 215 \mathrm{BP}$ ), y en las primeras excavaciones en la Sala I entre $19910-20900$ y $21480-22328$ calBP $2 \sigma$ (nivs 4 y 3: $17050 \pm 290$ y $18250 \pm 300 \mathrm{BP},{ }^{14} \mathrm{C}$ convencional), no parece guardar ninguna relación tecnotipológica con el Badeguliense francés, aunque algunas dataciones parezcan sugerirlo3.

Las condiciones medioambientales que presiden la sedimentación del Solutrense final de Las Caldas son de características muy frías y húmedas (GS-2c), y la fauna de los niveles incluye restos de dentina de Elephas $s p$ (mamut). Estos datos no son compatibles con la oscilación templada de Lascaux, con la que han sido relacionados en ocasiones, correspondiendo su sedimentación a un momento anterior que también sería más antiguo que el episodio templado asociado al Badeguliense antiguo francés. En esta época, los episodios de inundación de la cueva son frecuentes a causa de las crecidas del río hipogeo que circula por Caldas II, y se producen arrasamientos parciales de los depósitos anteriores. Así, en la Sala Il los niveles XIV y XIII aparecen biselados lateralmente por el desprendimiento y deslizamiento de una parte del paquete sedimentario magdaleniense, que se produjo con posterioridad a la sedimentación del Magdaleniense inferior. Asimismo, en el resto de la sala existe una discordancia erosiva entre la primera ocupación del Magdaleniense inferior (nivel XIII) y el nivel XIV (Fig.2), a causa de estas inundaciones. En la Sala I, a su vez, los niveles solutrenses que coronan la secuencia muestran análogas alteraciones y erosiones parciales junto a las gateras laterales, motivadas por estas inundaciones durante la sedimentación de los niveles 6 a 4, y también posteriormente generándose cubetas de erosión. En cambio, en la zona del Pasillo de entrada ${ }^{4}$ los mismos niveles están mejor conservados.

En cuanto a la interpretación sedimentológica de los niveles XIV y XIII de la Sala II, M. Hoyos apuntaba en unas observaciones preliminares (1995), con datos parciales del inicio de las excavaciones que no pudo completar por su prematura desaparición, que Lascaux pudiera ser el contexto paleoclimático del primer nivel magdaleniense (nivel $\mathrm{XIII)}$, ya que se presentaba erosionado a techo y discor- dante con el XIV; en este mismo estadio situaba el Magdaleniense arcaico de Rascaño (nivel 5). Pero los resultados de las excavaciones excluyeron esta interpretación (CORCHÓN, 1999), mostrando las dataciones ${ }^{14} \mathrm{C}$ (AMS) que el citado hiatus representa una amplitud cronológica (20478 - 21195 a 18051 - 18597 calBP) que desborda aquél breve estadio polínico. Y las inundaciones de las salas que producen estos arrasamientos no son susceptibles de paralelismo cronológico con el citado episodio polínico, carente de significación climática universal, sino que se trata de la manifestación local de una época muy fría y húmeda, que evacúa al exterior los caudales de agua de un karst abierto al exterior a través de numerosos conductos y con un río hipogeo circulando por Caldas II en la actualidad.

\subsection{Procesos Tecnológicos del Solutrense Final de Las Caldas}

En Las Caldas, la geometría de los depósitos muestra que el Solutrense final ocupaba todos los espacios habitados de la cueva (salas I y II; Pasillo I), y las dataciones disponibles también apuntan a la coetaneidad de los niveles. Pero su conservación ha sido desigual, por las citadas alteraciones postsedimentarios. Respecto de las industrias líticas y óseas, la similitud del registro arqueológico permite relacionar el nivel XIV (Sala II) con la secuencia de niveles 3 a 5 (Pasillo y Sala I), todos ellos producto de sucesivas ocupaciones de las estancias por pequeños grupos con una misma cultura material.

Las cadenas operativas líticas identificadas y estudiadas en los niveles de ambas salas presentan una gran homogeneidad, y se caracterizan por la diversificación de las materias primas y el uso de la cuarcita y el sílex en porcentajes similares. Se tallan materiales silíceos locales (sílex de Piedramuelle y Piloña) en una proporción mayor que en los niveles subyacentes, aunque también se han tallado sílex alóctonos de gran calidad, como el Flysch vasco (Barrika) y el francés (Bidache), y en menor medida sílex de Chalosse, Treviño y Urbasa. Respecto de la cuarcita, se trata de un material abundante en el entorno de la cueva, y en general en toda la cuenca del Nalón, y algunas variedades ofrecen excelentes condiciones para la talla -particularmente la cuarcita Barrios-, lo que explica su frecuente utilización durante el Solutrense superior. Es precisamente el uso preferente de la cuarcita lo que determina, en gran medida, que los productos de talla producidos en su explotación sean menos laminares y más espesos que los obtenidos del sílex (Fig.3).

\footnotetext{
3 Badegouliense antiguo o Magdaleniense 0, datado en el Abri Frisch (Indre), n.6, en $17960 \pm 350$ BP; en Laugerie Haute (n.18-20) en 18260 \pm 360 BP; en Vers (Lot) en $19150 \pm 100$ BP (DUCASSE et al., 2014). Según la Palinología, se desarrolló durante la Oscilación de Lascaux, pero tampoco existe unanimidad en lo relativo al contexto paleoclimático, ya que Laville y Paquereau situaban el Badegouliense antiguo de Laugerie Haute (nivs 18 a 20) en el Dryas I. Respecto del Magdaleniense I -"reconvertido" a Badegouliense reciente-, con una duración mayor, se extendería entre $17320 \pm 460$ BP en Pégourie (Lot), $17130 \pm 350$ en Abrigo Frisch (n.3), y $17040 \pm 440$ en Laugerie Haute, hasta $16800 \pm 170$ y $15980+150$ BP fecha en la que estaría presente en Vers. El frio ambiente del Dryas I se dejaría sentir ya en el n.3 del Abrigo Frisch (Badegouliense reciente).

${ }^{4}$ Hoyos estimaba que el máximo frío se produce en el nivel 4 (Pasillo), produciéndose entonces la crioturbación de los niveles inferiores en las zonas cercanas a la boca, como muestra la estratigrafía del Pasillo I.
} 
Al avanzar la secuencia del Solutrense superior sensu stricto, en los niveles que ocupan el techo del tramo (por ejemplo, en los niveles 6 y 7 ) se percibe un cambio en esta tendencia, que se manifiesta en el incremento de la talla de materias silíceas, y al final del tecno-complejo solutrense se traduce en la comentada diversificación de las materias primas seleccionadas para la talla. Estos cambios son graduales y progresivos, de modo que en los niveles 3 a 5 y XIV se encuentran sílex alóctonos y se observa cómo el Flysch (6,2\%) supera a otros sílex locales de calidad como Piloña (2,5\%). Estos datos contrastan, vivamente, con lo observado a propósito del denominado Badeguliense levantino y el Badeguliense francés, en los cuales la tendencia general es la contraria en lo relativo a las materias primas utilizadas para la talla: la monotonía, limitándose casi exclusivamente a la talla de cuarcitas.

Técnicamente, los niveles del Solutrense final de Las Caldas muestran porcentajes de talla no laminar elevados, destacando las lascas y las lasquitas como grupos mayoritarios: $69 \%$ en los niveles 3 a 5 de la Sala I en total, y $63 \%$ en el nivel XIV de la sala II. A su vez, el índice de corticalidad alcanza el 10\% de los soportes en el Solutrense Final, lo que indica una modalidad de talla poco sistemática en la producción de soportes grandes y medios, a partir de núcleos informes y globulares que son intensamente aprovechados. Y también revela que una parte de los soportes proceden de una talla primaria realizada en la cavidad. Por el contrario, los núcleos de laminillas recuperados en el nivel XIV presentan un alto grado de sistematización, lo que indica una talla organizada que produce núcleos prismáticos. Este dato resulta coherente, además, con la buena representación que alcanzan las hojitas retocadas entre los productos retocados.

En cuanto a los útiles del nivel XIV (Fig. 3), presentan una gran similitud con los recuperados en los niveles 3 a 5 de la Sala I, asimismo clasificados en el Solutrense Final. Ya se ha comentado la disminución relativa del porcentaje de foliáceos, patente en los niveles finales del Solutrense. Este hecho, si bien contrasta con el elevado índice que ofrecen estos útiles en algunos niveles del Solutrense superior, no implica que los foliáceos sean irrelevantes dentro del conjunto lítico, ya que su índice sigue siendo relativamente alto, con cinco ejemplares en el XIV (3,2\%) y veinticinco en los niveles 3 a 5 (6\%), y los tipos siguen siendo variados: hojas de laurel, de sauce y puntas de muesca. Además, resulta significativo que en los niveles finales se han identificado unos procesos tecnológicos destinados a la producción de hojas de laurel y puntas de base cóncava semejantes a los del Solutrense superior de Las Caldas. Para las hojas de laurel, en concreto, se trata de la cadena operativa 1, estudiada anteriormente (CORCHÓN et al., 2013). Finalmente, el estudio realizado con microscopía óptica ${ }^{5}$ ha permitido caracterizar e identificar las lasquitas producto del retoque de los foliáceos en estos niveles finales, confirmando la continuidad del proceso tecnológico aplicado para la configuración de los foliáceos, que ya estaba desarrollado anteriormente . $^{\text {. }}$

Estos hechos cuestionan la interpretación de un sector de la investigación acerca del carácter intrusivo de estos foliáceos, sosteniendo que corresponderían a niveles del Solutrense superior que habrían sido introducidos en los niveles por procesos de alteración sedimentaria (AURA et al., 2012). Este frágil argumento -que se sustenta en un estudio simplemente formal de los materiales, desatiende la realidad estratigráfica y los procesos tecnológicos implicados en la producción de los foliáceos, para respaldar la identificación de un "Badeguliense" de tipo francés en estos niveles.

Otros rasgos que caracterizan los últimos niveles solutrenses de Las Caldas en ambas salas, además del descenso en el número de los foliáceos, son el equilibrio entre los índices de raspadores y buriles, aquéllos sobre lascas retocada y sobre hojas, y éstos con un neto predominio de los diedros, así como el peso de los útiles del sustrato. Este último es un grupo numeroso en el que destacan los astillados (4-5\%) y los denticulados (ca.7\%), abundando también las lascas con retoques continuos que pueden llegar a ser muy numerosas (5 a 15\%). Pero las raclettes siempre son escasas: 12 ejemplares en los niveles 3 a 5 de la Sala I sobre un total de 424 útiles (2,8\%); y otras 3 en el nivel XIV de la Sala II en un conjunto de 157 útiles (1,9\%).

Otro dato de interés se refiere a los microlitos retocados, que alcanzan el $10 \%$ a causa de la presencia de hojitas de dorso acompañadas de algunas Dufour y escasos triángulos. Este hecho quizá esté relacionado con la pérdida de peso específico de los foliáceos en el utillaje destinado, específicamente, al armamento de caza.

En cuanto al material óseo de la Sala II, aunque la colección es pequeña y sólo incluye once soportes sistematizables por su alto grado de fragmentación, se trata de ejemplares muy típicos. Incluye cuatro azagayas, una de ellas completa con base monobiselada, cuatro colgantes -entre ellos dos caninos atróficos izquierdos de cervus hembra y macho-, y diversas superficies óseas grabadas. Entre estas últimas, destacan dos costillas del nivel XIV con grabados de gran interés: incisiones lineales y grupos de trazos pareados, una de ellas, y la otra con un haz lineal realizado con técnica de grabado-estriado. Paralelamente, los materiales óseos del Solutrense final de la sala I acusan

\footnotetext{
5 Microscopio estereoscópico Leica MZ 16 con zoom apocromático 16:1, con un rango de aumento de 7.1x a 115x y cámara digital incorporada Leica ICD; fuente independiente de luz fría, transmitida a través de doble haz de fibra óptica semirrígida que puede ser focalizada mediante lentes. Laboratorio de Prehistoria USAL.

6 Respecto del nivel 6, que fue incluido en la secuencia final en la reducida extensión de la cata 1- Pasillo en las excavaciones de 1971-73 (Corchón 1981), ya se ha indicado que su excavación extensa en la Sala I no permite asociarlo con claridad al Solutrense final. Así, aunque las alteraciones postsedimentarias son importantes en las épocas de inundación de la sala, sus características se aproximan más al Solutrense superior (niveles 7 a 12) que al final (niveles 5 a 3).
} 
una escasez y conservación deficiente análogas. Se trata de una colección de 15 soportes más variados, la mitad de ellos grabados. Destacan cuatro azagayas circulares y ovales, una de ellas con doble bisel, dos ejemplares con grabados lineales, un punzón de economía sobre peroné, también grabado, una varilla cuadrangular y ejemplares únicos de aguja, canino atrófico perforado, tensor y compresor. Sobresalen en el conjunto tres plaquitas con grabados lineales (Fig. 5).

En suma, se trata de un conjunto poco numerosos pero típico, estrechamente relacionado con aquellos otros más ricos en materiales y mejor conservados que caracterizan los niveles del Solutrense superior subyacente. Quizá lo más destacable sea el peso creciente de las azagayas en los niveles del Solutrense final, ya que su peso relativo en los conjuntos es muy elevado, teniendo en cuenta que son escasas las piezas óseas identificables. Y es verosímil que este hecho esté relacionado con la paralela disminución del peso específico de los foliáceos -las hojas de laurel y puntas de muesca- en los conjuntos, ya que se trata de utensilios relacionados con actividades esenciales de subsistencia, como armamento de caza.

Ya se ha comentado el clima muy frio y húmedo que preside la sedimentación de los niveles. En ellos se reco- gieron fragmentos de placas de dentina de molares de Elephas sp. (Mammuthus), en niveles del Solutrense superior (9 a 7) y final (4-5), tanto en las primeras campañas, donde fueron identificados por E. Aguirre, como en las posteriores que estudió J. Altuna. Aunque son restos poco numerosos, están acompañados de gruesos fragmentos no modificados y de placas de marfil trabajadas como colgantes, así como de restos diversos grabados con series lineales en paralelo (Solutrense superior) y con motivos lineales (Solutrense medio). Todo ello documenta el aprovechamiento del marfil de mamut como materia prima durante toda la secuencia del Solutrense.

El resto de las especies documentadas son el Cervus elaphus, que domina en todos los niveles, seguido de Rupicapra rupicapra, y con menos efectivos de Capra pyrenaica y Equus ferus. En cuanto a las épocas de captura, resulta revelador el elevado índice de restos juveniles e infantiles de ciervo, dos de los cuales fueron cazados en el primer verano de su vida y el resto entre los 8 y 28 meses, mostrando el modo de vida y actividades estacionales de los grupos que ocuparon la cavidad en el periodo estudiado. Por otra parte, se han encontrado restos de individuos infantiles en todas las especies citadas, que son las cazadas mayoritariamente. Estos hechos nuevos parecen

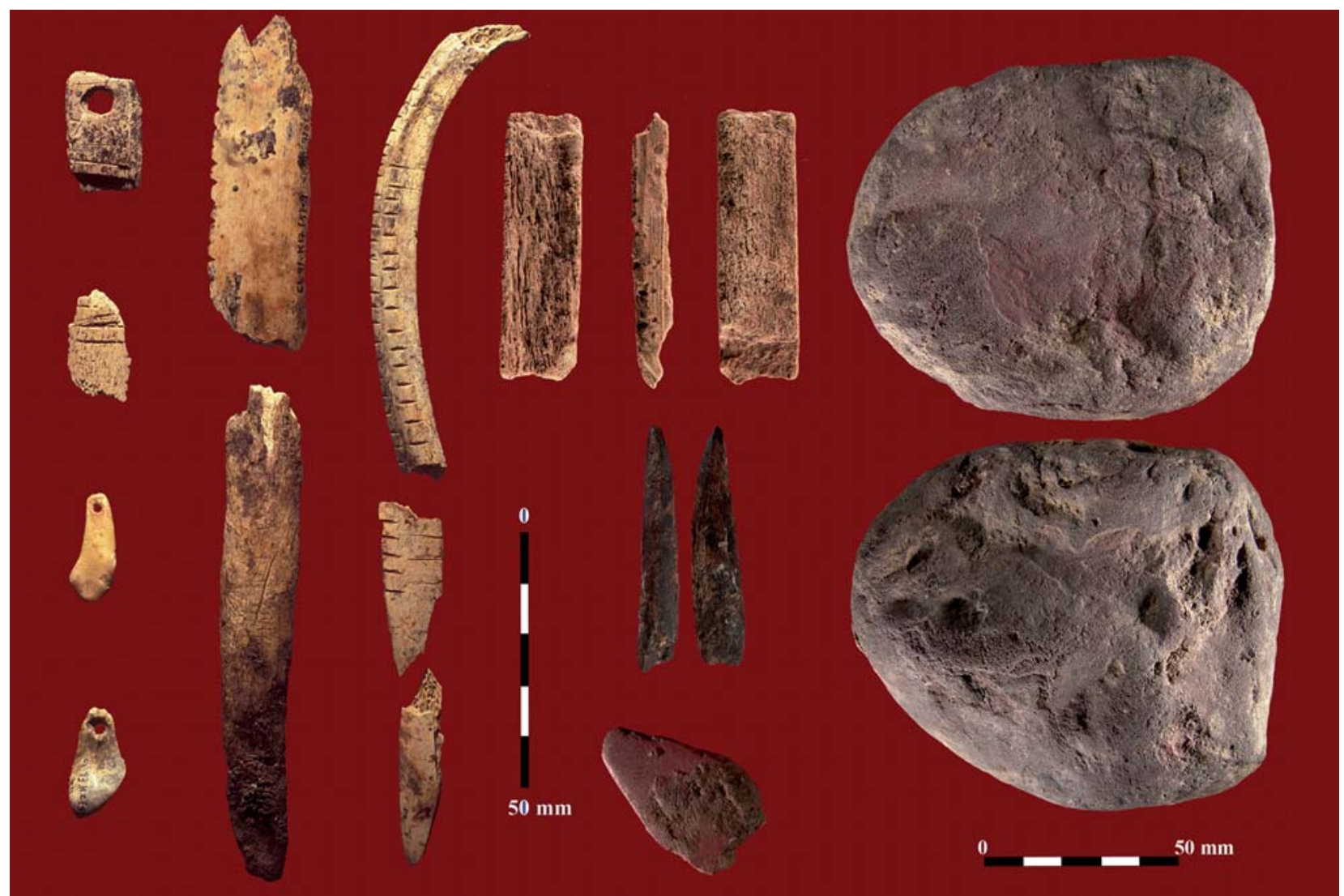

Fig. 4. Las Caldas, industria ósea y arte mueble. Industria ósea grabada y colgantes, Solutrense superior y final (izda: niveles 9 , 10 y XIV). Centro: varilla cuadrangular; azagaya grabada (4 trazos oblícuo-paralelos) e impregnada de ocre; lápiz de hematites rayado y machacador de ocre (niveles 3 a 5). / Las Caldas, bone industry and chattel art. Carved bone industry and pendants, late and end Solutrean (left: levels 9, 10, and XIV). Centre: quadrangular rod; carved spear (4 oblique-parallel lines) and impregnated with ochre; scratched haematite pencil and ochre crusher (levels 3 to 5). 
sugerir que practicaron una caza preferente de los grupos formados por las hembras y sus crías, según los datos que aportan el reciente estudio de la fauna de Las Caldas (ALTUNA y MARIEZKURRENA, e.p.).

\subsection{Otras evidencias solutrenses en el valle del Nalón}

El abrigo de Entrefoces-Cueva del Molín, habitualmente considerado un yacimiento típico del Magdaleniense inferior avanzado (niveles B y A), probablemente contiene un registro estratigráfico más complejo, que está aún pendiente de estudio exhaustivo y de la publicación de los registros (GONZÁLEZ-MORALES, 1990, 1992; GONZÁLEZ-SAINZ, 1989, GONZÁLEZ-SANZ et al., 2013). Un problema interesante se refiere a los niveles subyacentes, para los que apenas existen algunos datos puntuales de los conjuntos líticos recuperados (C-E1), que aún permanecen inéditos. No obstante, algunos rasgos del registro estratigráfico, como la industria ósea de los niveles C, D y E, sugieren que los niveles subyacentes al Magdaleniense inferior B pudieran contener elementos similares a los que conocemos del Solutrense superior y final de Las Caldas, como las azagayas con aplastamiento central que están documentadas en el Solutrense superior del Nalón (Las Caldas).

La adscripción de todos los niveles al Magdaleniense Inferior se sustenta en la ausencia de foliáceos, y en la interpretación de la datación obtenida en el nivel B como un término antequem. Sin embargo, la existencia de un arte parietal pre-magdaleniense en el mismo abrigo, en el sector conocido como cueva del Molín, recientemente estudiado (GONZÁLEZ SAINZ et al., 2013), pone de manifiesto la presencia en el lugar de grupos humanos anteriores, durante el Solutrense. En lo que se refiere a la industria ósea, no hay que desdeñar el dato publicado de la presencia de azagayas con aplastamiento central entre los materiales de los niveles D a E1, ya valorado anteriormente. Este tipo de azagaya es característico del Solutrense superior regional, tanto en el valle del Nalón como en los territorios centrales de la Cornisa cantábrica. El abundante registro óseo de estos niveles, unido a los pocos datos existentes acerca de la industria lítica del nivel E -con un tipo de talla realizada principalmente en cuarcita, a base de lascas, con núcleos discoides y globulares y numerosos útiles de sustrato- (VAQUERO, 2012), pudiera ajustarse a lo que conocemos como Solutrense superior y final del Nalón.

En todo caso, una ocupación pre-magdaleniense de estas características sería coherente con el resto de ubicaciones en el territorio del Nalón, sin que sea necesario buscar una explicación para la presencia de estos elementos óseos en otra posible facies del Magdaleniense inferior, ya que las azagayas con bisel central o terciado están presentes en numerosos yacimientos del
Solutrense superior y final regionales, como Cueto Mina (E), Las Caldas (11), La Riera, y en el Solutrense final de Altamira?.

Respecto del Covacho de Candamo, se trata de un pequeño habitáculo existente a unos 40 metros de la cueva de La Peña que albergaba un yacimiento de unos $2 \mathrm{~m}$. de espesor, actualmente vaciado. Las antiguas excavaciones (HERNÁNDEZ-PACHECO, 1919) exhumaron restos de ocupaciones del Solutrense superior, con elementos diagnósticos como algún foliáceo, un colgante sobre canino de Cervus perforado y macro-industria de cuarcita. Esta colección, en su estado actual seleccionada y con escasos elementos diagnósticos, se conserva en el Museo Nacional de Ciencias Naturales. Posteriormente, las excavaciones de F. Jordá en los años sesenta añaden al Solutrense otros elementos nuevos, como los restos de otra ocupación que atribuye al Magdaleniense inferior, todo ello depositado en el Museo Arqueológico de Asturias. En todo caso, estos dos estadios están documentados en el arte parietal de los grandes paneles de la cueva de La Peña de Candamo. Además, un reciente estudio de restos de suelos con fauna, ocre y carbón, así como diversas evidencias de actividades gráficas, localizados en el fondo de la Galería Batiscias a la cual se accede desde el Gran Salón de los Grabados de la cueva de La Peña-, incluye una macro-industria de cuarcita comparable a la del Covacho. En estos suelos se han obtenido varias dataciones 14C (AMS), cuyos resultados evidencian la frecuentación de la cavidad durante el Solutrense superior y final, en un intervalo temporal estimado a $2 \sigma$ Cal BP: 22360 a $20670^{8}$.

\section{3.- REGISTRO ESTRATIGRÁFICO DEL MAGDA- LENIENSE INFERIOR}

\subsection{Los niveles de la Cueva de Las Caldas}

En la Sala II de Las Caldas se superpone al nivel XIII, que representa la primera ocupación magdaleniense de la cueva, una secuencia de otros tres niveles (XII inf., XII y $X I)$, pudiendo considerarse todo el tramo arqueológicamente uniforme. La principal alteración de este potente depósito se produce, como se ha comentado, a causa del frio y la humedad al desprenderse una parte del paquete sedimentario formado por los niveles XII inferior y XII, deslizándose a modo de colada hacia una gatera del muro derecho que comunica con Caldas II. Este desprendimiento biseló lateralmente los depósitos cercanos, pero afectó sólo a una zona reducida de los depósitos (cuadro $\mathrm{H}-4$ : Fig. 2). Destaca el hallazgo en el techo del nivel XI, a la entrada de la sala, de un Hogar construido con grandes bloques calizos que circundan la cubeta, conservado excelentemente al estar sellado por los limos estériles de inundaciones posteriores. Estos limos (nivel X: >40 espesor),

\footnotetext{
7 Se reproducen en Corchón 1994: 138, Fig.2, y 1999b: 50 y Fig.4.

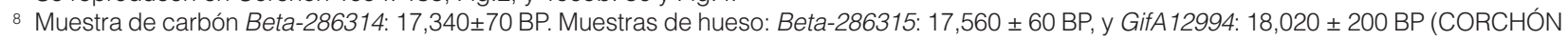
et al., 2015).
} 
separan el Magdaleniense inferior del Magdaleniense medio (niveles IX y ss.) ${ }^{9}$, asegurando la integridad de ambas secuencias estratigráficas.

Este paquete estratigráfico, cuyas dataciones implican la ocupación de la cueva a lo largo un periodo de tiempo no excesivamente prolongado ( $2 \sigma$ cal BP: 18051 18597 a 17353 - 17917) (cf. Tabla.1 y nota 7), se sedimentó también en un clima muy frío y húmedo, registrando la fauna aportada al yacimiento especies estépicas (ALTUNA y MARIEZKURRENA, e.p.). Por tanto, la fase anterior, Magdaleniense arcaico (tipo Rascaño 5), no está representada en Las Caldas. Algunos datos de otros niveles coetáneos, como Riera 19, Rascaño 4 o la base de Altamira, también marcan la degradación climática que caracteriza este segmento temporal, y cuyo rigor persiste aún hacia el techo de la secuencia (Juyo, Rascaño 4-techo y base de Rascaño 3).
Al respecto, los análisis efectuados en Las Caldas revelan que no se han conservado restos suficientes de pólen, pero los otros yacimientos mencionados muestran un paisaje dominado por las gramíneas y asteráceas de tipo xerófilo, con taxones estépicos y tasas de pólenes arbóreos bajas. La fauna es igualmente indicativa, con mamíferos adaptados a climas de tipo estepario. Es el caso del reno (Rangifer tarandus), presente en la fauna del Nalón (Las Caldas XII y XII inferior; La Paloma 8), y que se extendió entonces por toda la Región Cantábrica ${ }^{10}$. En lo que se refiere al registro de Las Caldas, además del reno se encuentran otras especies estépicas, como el rinoceronte lanudo (Coelodonta antiquitatis: n.XII inf), y el mamut, éste en forma de gruesos fragmentos de marfil parcialmente quemados (nivel XI-Hogar), y de varias azagayas biseladas fabricadas en ese material a todo lo largo del tramo (CORCHÓN, 1992).

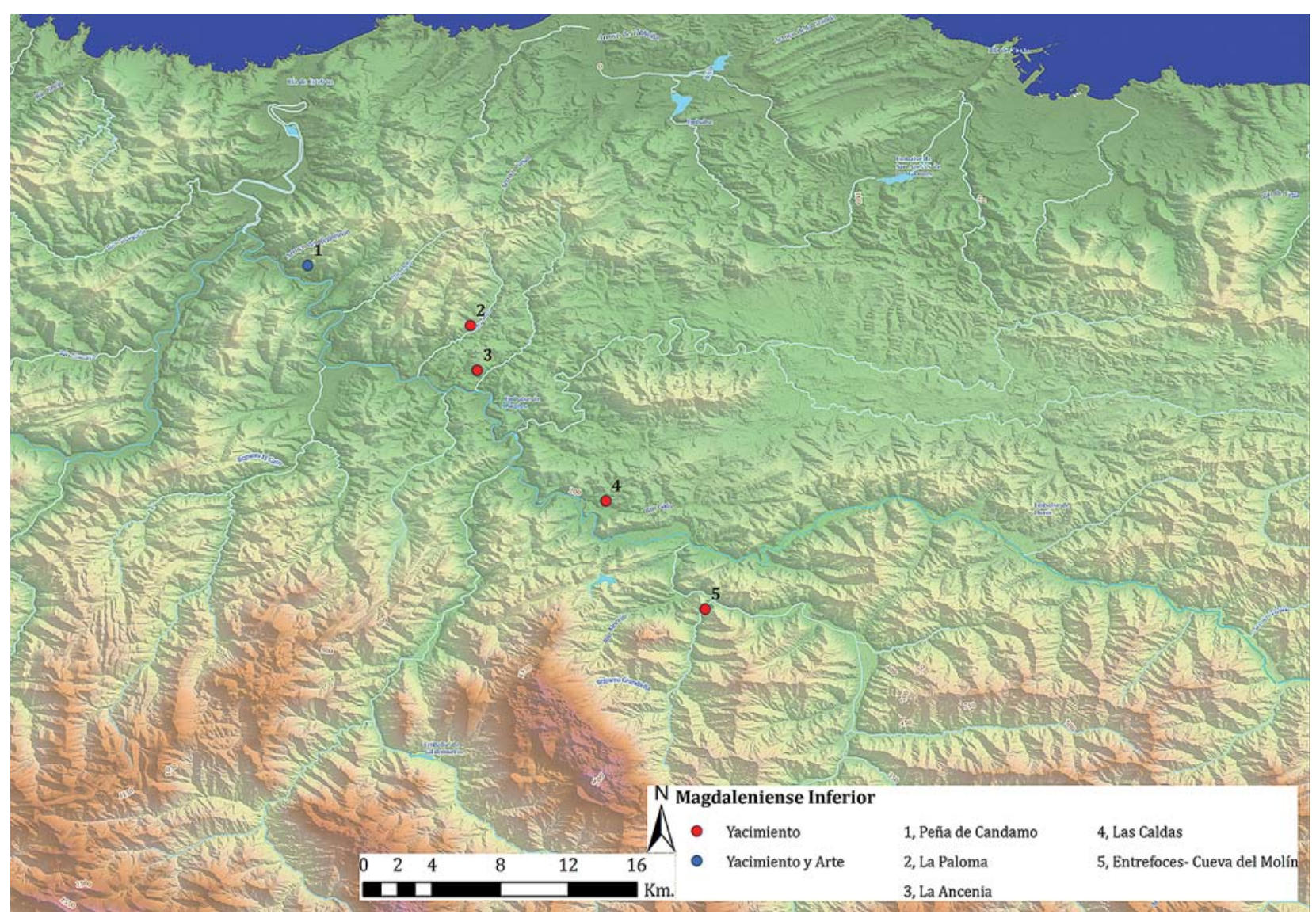

Fig. 5. Localización de los yacimientos y estaciones con arte del Magdaleniense inferior en el valle del Nalón. / Layout of the sites and centres with early Magdalenian art in the Nalon Valley.

\footnotetext{
9 Una muestra tomada de la cubeta del hogar arroja 13,755 \pm 120 BP. La fecha resulta algo reciente, probablemente rejuvenecida por las carbonataciones secundarias que encostran el techo del nivel XI y el Hogar. Así, la datación del n. XII (14495 \pm 140$)$ puede estimarse representativa del techo del Magdaleniense inferior de Las Caldas, y coherente con obtenida en su base (15165 \pm 160 BP), siendo arqueológicamente uniformes las industrias.

${ }^{10}$ En Cantabria se encuentra en El Castillo 7 y 8; en el País Vasco en Urtiaga F y Erralla V (CASTAÑOS, 1980; CORCHÓN, 1992; ALTUNA, 1996). En este último, su coetaneidad es segura al estar datado el nivel entre $15740 \pm 240$ a $16270 \pm 270$ BP (ALTUNA et al., 1984; ALVAREZ y JÖRIS, 1998: 81), en un contexto frío y seco con acusados procesos de gelivación (base del Dryas lb de la cronología polínica).
} 
Sin embargo, el registro de Las Caldas revela que la subsistencia de estos grupos de cazadores-recolectores se basaba en caza del ciervo, la especie mejor representada en todos los niveles. Y se percibe también cómo, paulatinamente, se diversifican las especies capturadas e incrementan su presencia otras de mayor rendimiento cárnico como el caballo. Se trata de un cambio paulatino, que se intensifica al avanzar la secuencia (niveles XII y XI), quizá como respuesta a la necesidad de asegurar la subsistencia de un mayor número de pequeños grupos sociales, en un ambiente muy riguroso. En cuanto a las estrategias de caza, el registro de los cérvidos incluye algunos ejemplares juveniles e infantiles, y también un neonato o perinatal. La presencia de estos especímenes infantiles alude prácticas de caza del ciervo durante el verano, aunque no puede descartarse la captura de esta especie durante todo el año, ya que el volumen de restos recuperados es muy elevado.

Por otra parte, el Magdaleniense inferior de la cueva de Las Caldas presenta algunas características destacadas. La primera se refiere a la excepcional conservación de los registros en la extensa secuencia formada por cuatro niveles sucesivos de ocupación. Ello implica, probablemente, que pequeños grupos sociales visitaban el valle del Nalón de forma reiterada, posiblemente con carácter estacional. La base se ha datado por ${ }^{14} \mathrm{C}$ (AMS) en $15165 \pm 160 \mathrm{BP}$ (nivel XIII) y el techo en $13755 \pm 120 \mathrm{BP}$ (nivel XI). Pero la parte superior de este último nivel, así como el hogar conservado en su techo, presentaban procesos de cementación por carbonataciones que, según apunta el geólogo M. Hoyos (1995), han rejuvenecido la fecha. Por ello, la obtenida en el nivel siguiente (n.XII) se ajustaría más a la realidad. En este sentido, las observaciones geológicas preliminares de M. Hoyos indican que los niveles XI-XII sedimentológicamente pueden considerarse uniformes, resultando por ello más convincente la datación ${ }^{14} \mathrm{C}$ AMS de éste último: 14,495 \pm 140 BP.

En síntesis, la horquilla temporal delimitada por estos resultados, y su coherencia con la datación ${ }^{14} \mathrm{C}$ AMS del siguiente (XII inf.: 14,835 \pm 130 BP), apuntan a una duración estimada para estas ocupaciones inferior al milenio. La uniformidad técnica y tipológica de las industrias a lo largo del tramo, así como su cronología posterior a la fase arcaica del Magdaleniense cantábrico e inmediatamente anterior al Magdaleniense medio antiguo, también avalarían el carácter uniforme y corto en el tiempo de los asentamientos en la cueva de Las Caldas durante el Magdaleniense inferior.

Una segunda característica destacable es el carácter homogéneo de las industrias, de techo a base, lo que implica una importante estabilidad en la cultura material con un peso creciente del instrumental microlítico, especialmente de los triángulos. Estos niveles incluyen azagayas biseladas, abundantes hojas retocadas y núcleos, en un conjunto en el cual sobresale el peso específico del utillaje microlaminar (ca. 48\% en promedio; $60 \%$ en el nivel XII), integrado por numerosas hojitas de dorso, triángulos y ho- jitas-escaleno, un número menor de Dufour con algún trapecio y segmento de círculo. El marfil de mamut (Elephas sp.) también en este caso se ha utilizado como materia prima para fabricar azagayas y varillas, y está presente además en forma de fragmentos en curso de procesado.

\section{Las industrias líticas}

Este tecno-complejo se caracteriza, en primer lugar, por el uso de sílex locales -muy accesibles en el entorno de la cueva-, y en menor medida de otros foráneos para la talla lítica, en detrimento de la cuarcita que decae notablemente. Los datos revelan que la intensidad de este cambio de tendencia en la selección de las materias primas es creciente: $62,8 \%$ de sílex en la base (XIII), y en torno al $80 \%$ en los siguientes (XI, XII-inf). Respecto de los sílex alóctonos, aunque su presencia es moderada, implica la existencia de una amplia movilidad ya que proceden de áreas fuentes alejadas más de 200 km de la cueva, y quizá de redes de contacto con otros grupos sociales de la Cornisa cantábrica (CORCHON, TARRIÑO y MARTíNEZ, 2009) (Fig.6 y 7).

En estos niveles, los soportes de talla no retocados presentan elevados índices de lascas y lasquitas, que son los grupos mejor representados (L: 19 a 37\%; LQT: 18 a $39 \%$ ) , seguidos de las hojitas. Esta tendencia no laminar es más acusada en la cuarcita, cuyos soportes son espesos y cortos. En cambio, la tendencia se invierte en los útiles cuyos soportes presentan elevados índices de laminaridad que oscilan entre el 78,9\% y el 56,6 \%. Estos datos ponen de manifiesto que para la talla de los útiles se han seleccionado los soportes más laminares, desechándose los menos aptos.

Estas particularidades observadas en la talla, concuerdan con los resultados del análisis de la tipología de los núcleos, en su mayoría informes ${ }^{\circ} 45 \%$ ) y en menor medida prismáticos (33\%). Del mismo modo, la mayoría de los núcleos de sílex son prismáticos, mientras que los de cuarcita presentan un sistema de explotación menos sistemático.

En lo que se refiere a los utensilios retocados, su estudio revela como característica más llamativa el elevado porcentaje de microlitos, oscilando sus porcentajes entre $18 \%$ y $52 \%$ del total de útiles. Engrosan estos porcentajes el alto índice de hojitas de dorso, cuyo peso específico oscila entre el $10 \%$ y el $33 \%$, y la notable presencia de triángulos cuyo número se triplica al avanzar la secuencia: 5\% a $6 \%$, frente al $2 \%$ que alcanzaban en la base o nivel XIII. De la importancia en los microlitos nos da idea el hecho de que son los objetos más numerosos en todos los niveles, y su presencia relativa llega a quintuplicar a los buriles (n.XII: $52 \%$ y $10,22 \%$, respectivamente). En el caso concreto de los triángulos, superan a los raspadores en todos los niveles lo que justifica su caracterización como "Magdaleniense con triángulos" (CORCHÓN, 1993). Con ellos, en estos niveles se encuentra algún microburil y un trapecio (n.XII), así como cuatro segmentos de círculo (n.XIII y XII), evidenciando que el proceso de fabricación de estos microlitos 


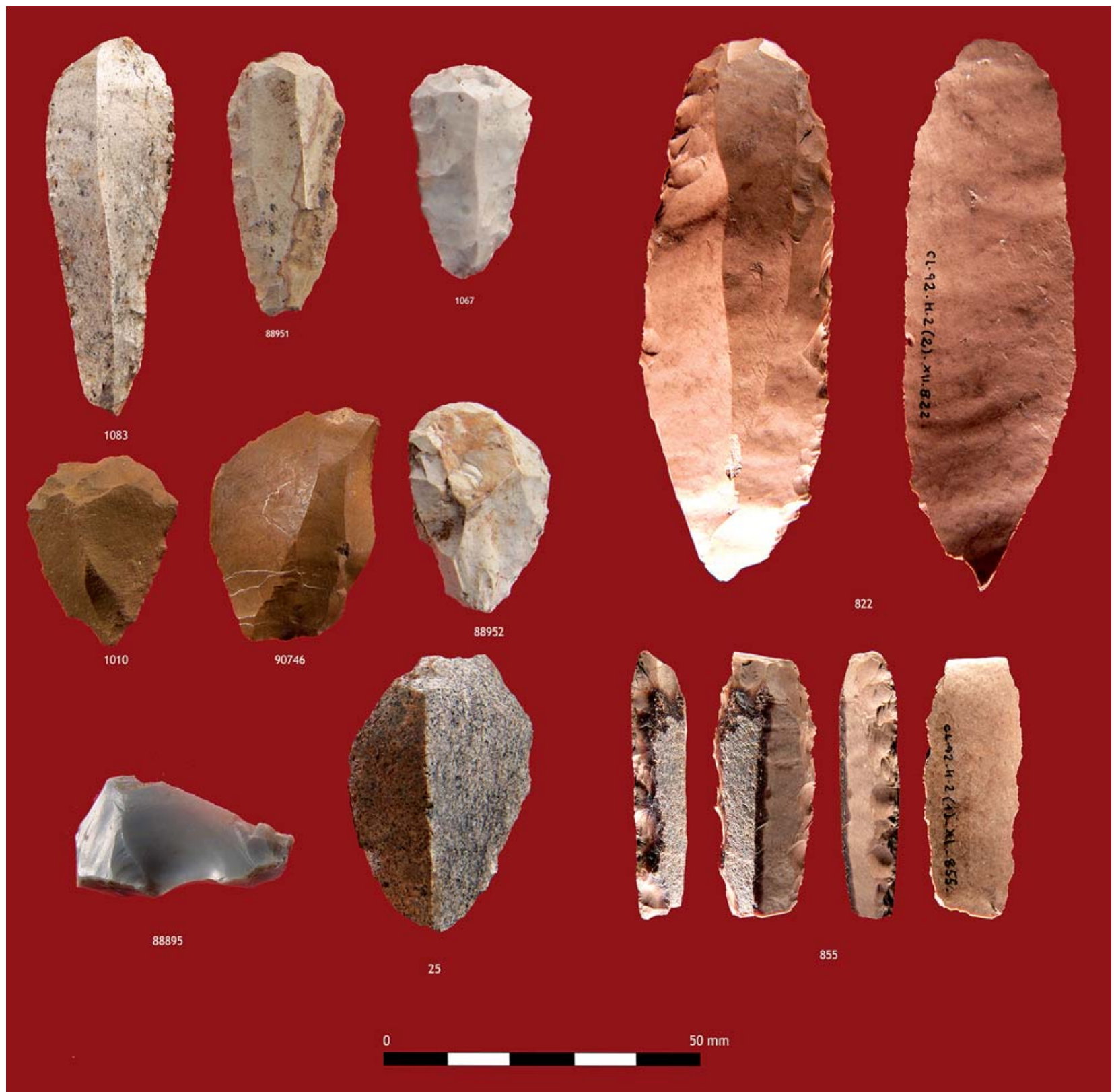

Fig. 6. Las Caldas, sílex del Magdaleniense inferior (Treviño: 822, 855) y Solutrense final (resto). Flysch Bidache (1083) y vasco (25), Chalosse? (88952), Urbasa (88951),brechoide (90746), local (88952,) e indeterminado (1010, 1067). / Las Caldas, early Magdalenian flint (Treviño: 822, 855) and end Solutrean (other). Flysch Bidache (1083) and Basque (25), Chalosse? (88952), Urbasa (88951), breccioid (90746), local (88952), and undetermined (1010, 1067).

se realiza en la misma cueva, y no sólo llegaron a la misma insertados en venablos y vástagos de armas (Fig.7).

La abundancia de hojitas de dorso determina también que el índice perigordiense sea elevado, ya que la presencia del resto de los útiles incluidos en este grupo es testimonial. Además del peso específico de los microlitos, caracterizan estos niveles los buriles (10 a 15\%) -destacando los diedros rectos, de ángulo y sobre rotura-, la disminución de los raspadores, y la abundancia de hojas retocadas ( 9 a $26 \%)$, entre ellas algunas hojas auriñacienses $(3,3 \%$ en el nivel XII inf.). Y también un moderado índice del sustrato, en el cual únicamente destacan denticulados y raederas, siendo las raclettes un útil testimonial $(0,3$ a 1,85).

\section{La industria ósea y el Arte mueble}

Al igual que sucede en las industrias líticas, el ajuar elaborado en hueso, asta y marfil ofrece una notable homogeneidad de tipos que afecta a todos los niveles, siendo especialmente numerosa la colección recuperada en el tramo superior. Las azagayas, con 35 ejemplares, representan un grupo muy numeroso y variado. Se trata de 

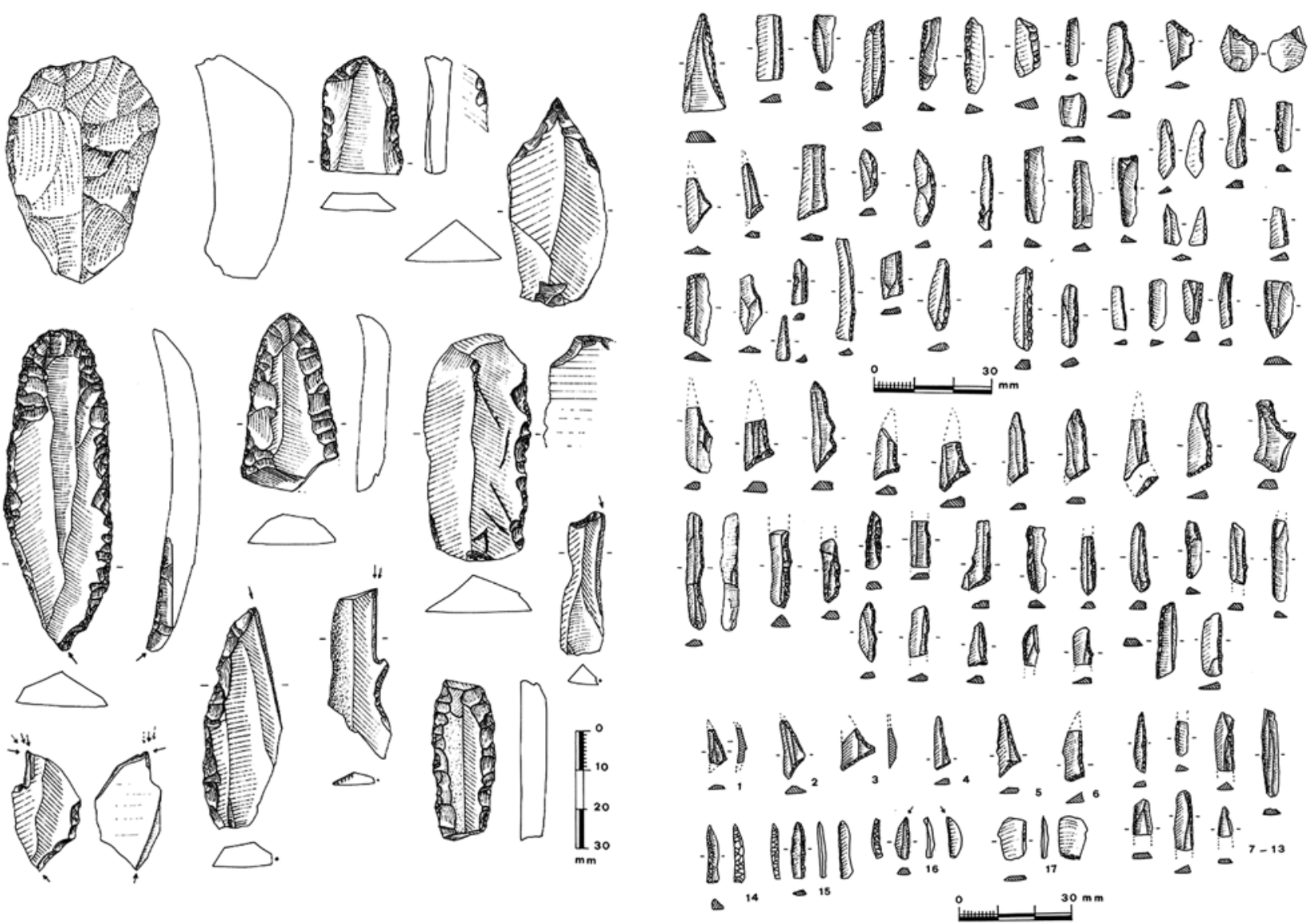

Fig. 7. Industria lítica del Magdaleniense inferior de Las Caldas: raspadores sobre lasca y sobre hojas retocadas, buriles, hoja auriñaciense, perforador y dentciulado (izda). Destaca la abundancia de hojitas retocadas y geométricos (dcha.). / The archaeological industry of the early Magdalenian of Las Caldas: scrapers on flake and retouched blades, burins, Aurignacian flake, piercer and denticulate (left). The abundance of retouched and geometric blades stands out (right).

puntas cilíndricas, en 13 ejemplares con la base trabajada en uno o dos biseles, y sus formatos son muy variados, coexistiendo azagayas cortas y robustas con otras puntas largas y esbeltas. Algunas ofrecen cortas acanaladuras en el dorso e incluso en el bisel. Esta especialización en los tipos se refleja también en la elaboración del ápice, ofreciendo dos ejemplares de base en monobisel una punta distal aplanada-espatulada y no la habitual cónica. Menos frecuentes son las azagayas de sección triangular y las aplanadas, en algunos casos con decoración lineal. Con ellas, superan la media docena los ejemplares de finas espátulas en hueso, y también las varillas semicilíndricas con incisiones transversales de sujeción en la base. En cuanto a la tecnología aplicada para trocear las astas de cérvido, numerosas matrices presentan surcos de extracciones y ranurados longitudinales dobles, que son habituales en los contextos magdalenienses, así como varillas en bruto con los estigmas de su extracción, todo ello muy alejado de las técnicas arcaicas de percusión que se han descrito para el Badeguliense (Fig. 8). En el nivel XIII se recogió, finalmente, un pequeño fragmento distal de propulsor grabado con series lineales, que relaciona esta secuencia con otras del Magdaleniense inferior cantábrico donde se conocen propulsores comparables (Castillo, La Riera).
En conjunto, la industria ósea de Las Caldas ofrece una gran semejanza con la documentada en la cercana cueva de La Paloma: Magdaleniense inferior y nivel 8. Y este paralelismo se extiende al registro mobiliar.

La documentación de Arte mueble de Las Caldas (CORCHÓN, 1993) ofrece unos motivos lineales y unos grafismos figurativos cuyo el estilo muestra un notable paralelismo con otros yacimientos del Nalón. Caracterizan este Magdaleniense las decoraciones regulares a base de series lineales, destacando un tubo en hueso de ave (La Paloma), y diversos colgantes sobre caninos de ciervo perforados y grabados con incisiones en paralelo. Una de las piezas más notables es una gruesa diáfisis distalmente utilizada como alisador, decorada con tres series regulares de incisiones en paralelo en los bordes, y con grupos de trazos pareados al dorso (Las Caldas). La Paloma y Las Caldas, finalmente, ofrecen registros comparables de armas decoradas con series lineales, particularmente en las azagayas (Fig.8).

La representación figurativa es escasa pero igualmente típica. De Las Caldas procede un asta de muda que es una matriz con huellas de extracción de varillas mediante ranurado-, grabada con una cabeza de caballo y dos cabezas de ciervo contrapuestas, a base de inci- 


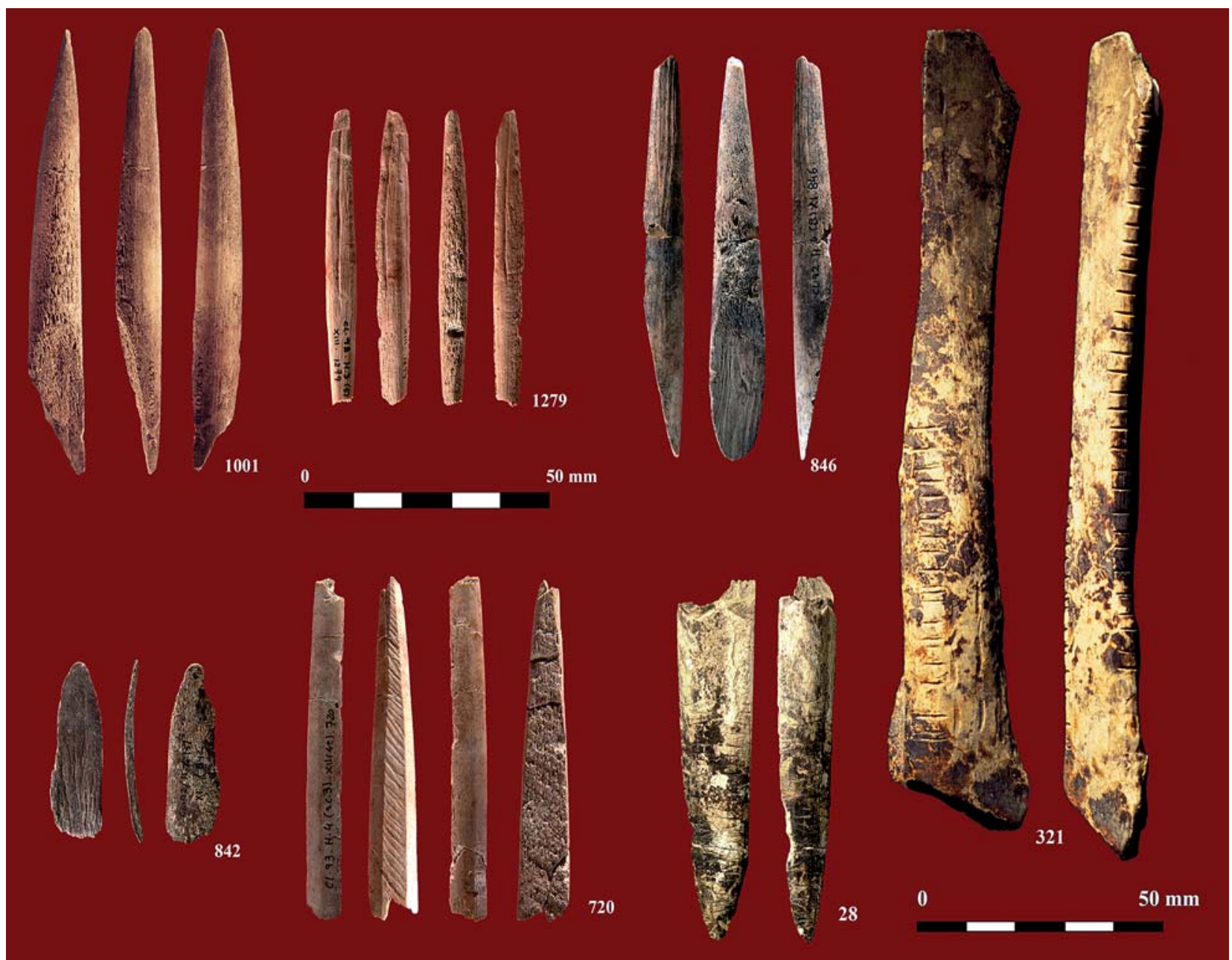

Fig. 8. Industria ósea del Magdaleniense Inferior de Las Caldas: azagayas biseladas, con ranuras, varillas grabadas y espátula. / The bone industry of the Early Magdalenian of Las Caldas: bevelled spears, with grooves, carved rods, and a spatula.

sión muy fina combinada con estriado irregular. Este estilo para representar los zoomorfos, de diseño simplificado a base de trazos lineales simples, comúnmente limitado a la cabeza y el cuello, con escasos detalles corporales y sin despieces interiores, se conoce también en La Paloma: una diáfisis grabada con una cabeza y cuello de una cierva, y una costilla con el grabado fino de otra cabecita, posiblemente de cierva.

\subsection{Otros registros del valle del Nalón}

A partir de las variables establecidas en el análisis de los niveles del Magdaleniense inferior de Las Caldas, se ha procedido a su comparación con otros niveles magdalenienses del valle del Nalón, a fin de valorar las posibles relaciones existentes entre los mismos. Sin embargo, la escasez de estudios sistemáticos impone serias cautelas en los resultados, ya que la mayoría de ellos permanecen inéditos o apenas se han publicado muestras muy pequeñas de los materiales recuperados en las excavaciones de los yacimientos.
El estudio tipológico del nivel B del Abrigo de Entrefoces, en primer lugar, revela notables paralelismos con algunos niveles de Las Caldas, como el XII y el XII inferior. Y la datación obtenida, Ly-2937: 14620 \pm 200 BP (GONZÁLEZ MORALES, 1990, 1992) lo sitúa en una horquilla temporal cercana (GONZÁLEZ SAINZ, 1989).

Este conjunto lítico muestra un neto predominio del sílex como materia prima fundamental, aunque en la colección se encuentran cuarcitas talladas de gran calidad. La preferencia por las materias primas silíceas para la talla explica, probablemente, los elevados índices de laminaridad de la colección, que incluye hojas de tamaño grande y mediano. Entre los útiles destacan los microlitos, y al igual que sucede en Las Caldas las hojitas de dorso son muy numerosas, con un 30\% del total. En cambio, los útiles del sustrato presentan un desarrollo moderado, destacando únicamente los denticulados que alcanzan $6 \%$ del total. Respecto de los buriles, la mayoría diedros, superan a raspadores representados por tipos simples y carenados. 
En cuanto a los niveles del Magdaleniense inferior de la cueva de la Paloma, plantean problemas tanto de naturaleza estratigráfica como otros derivados del almacenaje y la integridad de las colecciones. Los materiales depositados en el Museo Nacional de Ciencias Naturales de Madrid publicados (HOYOS et al., 1980), proceden de diferentes zonas y portan dos siglas diferentes: "M. inferior" y "Nivel 8", alusivas a su procedencia de zonas distintas del yacimiento. Pero los niveles no siempre fueron distinguidos con claridad en el transcurso de las excavaciones, y las colecciones han sufrido distintos cambios de ubicación. Por este motivo, se han englobado en el Magdaleniense inferior la totalidad de los materiales siglados como nivel 8 , los escasísimos restos con la referencia de niveles 9 y 10, y los que portan la sigla "Magdaleniense inferior" (Fig.9 y 10).

El conjunto lítico se caracteriza, globalmente, por el elevado porcentaje de raspadores, en su mayoría sobre lasca, frente a un menor número de buriles, mayorita- riamente nucleiformes y diedros. El hecho de que estos dos grupos representen el 50\% del total del material lítico retocado apunta a una selección del material, quizá realizado durante las excavaciones, ya que a principios del siglo XX era habitual recoger sólo los objetos característicos y desestimar los atípicos. Sin embargo, no concuerda con esta práctica el hecho de que la colección incluya 15 hojitas de dorso, lo que indica que la metodología de excavación aplicada fue más minuciosa de lo habitual, permitiendo recoger los microlitos. Por ello, es posible que se produjese la selección del material retocado al exponer y almacenar las colecciones. En cuanto a los útiles del sustrato, alcanzan el 17\% del total e incluyen abundantes denticulados y escotaduras. En suma, se trata de una colección lítica que no es fácilmente relacionable con los materiales de Las Caldas; pero no sucede lo mismo con la industria ósea y el arte mueble, que sí ofrecen notables semejanzas como se ha indicado.

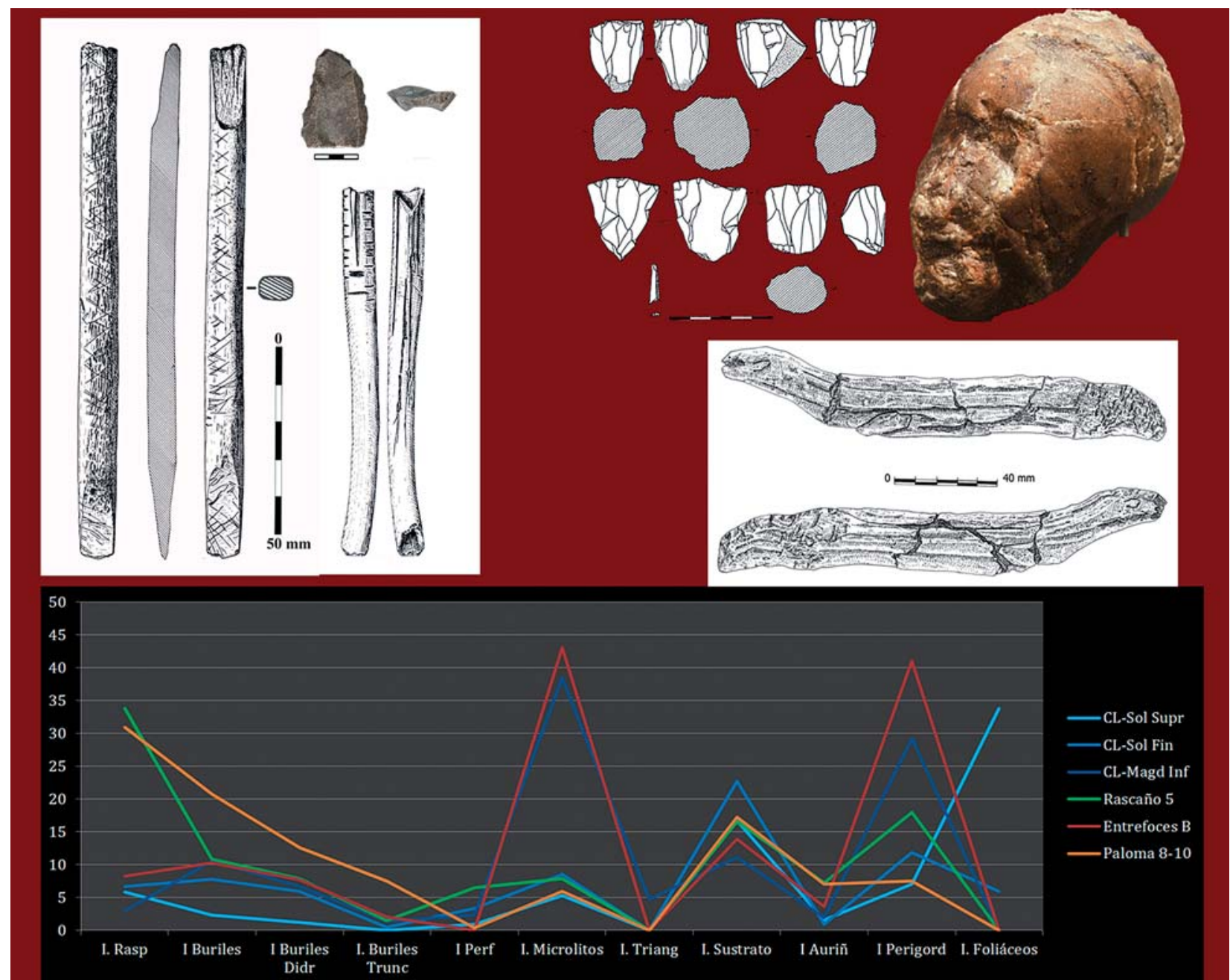

Fig. 9. La Paloma: azagaya biselada, tubo óseo grabados y raedera en cuarcita (arriba izq.). Entrefoces (B): núcleos (según González Sainz 1989), cabeza humana tallada sobre canto y escultura serpentiforme en asta (arriba drcha.). Abajo: gráfico comparativo de los índices tipológicos de los niveles estudiados. / La Paloma: bevelled spear, engraved bone tube, and side scraper in quartz (upper left). Entrefoces (B): cores (according to González Sainz 1989), a human head carved on stone and a serpent-like sculpture on antler (upper right). Below: a graphic comparing the typological indices of the studied levels. 


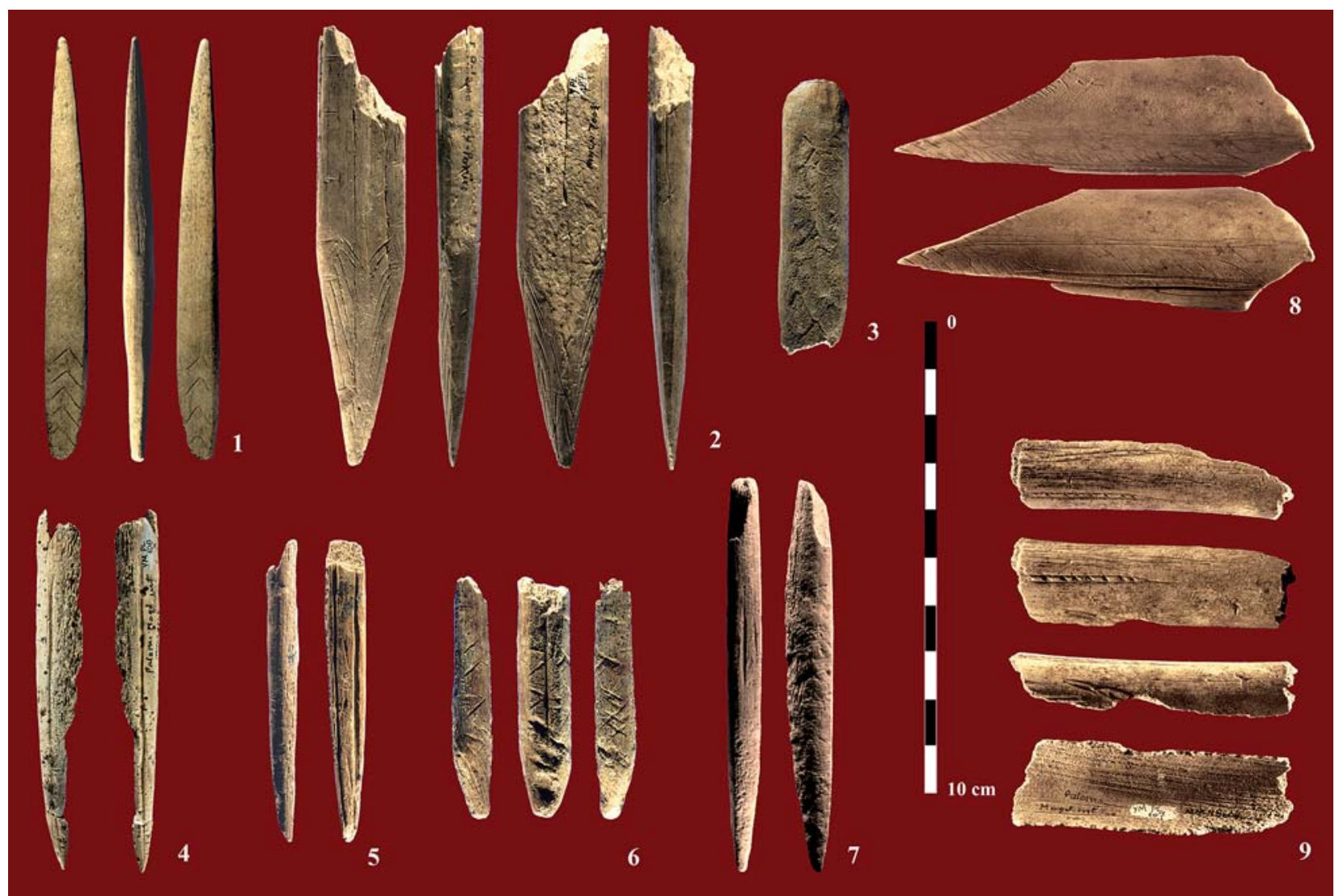

Fig. 10. Industria ósea y arte mueble del Magdaleniense inferior de la cueva de La Paloma: azagayas y alisador con decoraciones en espiga, lineales, dobles acanaladuras y motivos geométricos. Diáfisis grabadas con una cabecita de cierva (arriba) y husos-escaliformes y ¿cabecita de cierva? (abajo). / Bone industry and chattel art of the early Magdalenian in the La Paloma cave: spears and smoothing tool with decorations as tenons, linear, double canaliculates, and geometric motifs. Carved diaphyses with a deer head (above) and scalariform-spindles, and a deer head? (below).

\section{4.- DISCUSIÓN}

Los datos proporcionados por los registros estratigráficos de la cueva de Las Caldas, y su comparación con otros de los yacimientos del valle del Nalón, permite apuntar que no está acreditada la existencia de una ruptura entre los procesos tecnológicos que caracterizan Solutrense superior respecto del Solutrense final, como señala un sector de la investigación. Por el contrario, los datos analizados apuntan a un proceso de cambio gradual en los modos de talla, que se plasma en una disminución gradual en la selección de la cuarcita como materia prima fundamental, sustituida por el uso creciente del sílex en los procesos de talla, particularmente de los sílex alóctonos. Las industrias líticas del Solutrense final de Las Caldas revelan que existe continuidad, respecto del proceso de desarrollo de las técnicas de talla propias del Solutrense, que se inicia en el Solutrense medio y que alcanza su máximo auge en el Solutrense superior. Por otra parte, aunque es un hecho constatado que a finales del Solutrense no se alcanzan en el Nalón los elevados índices de foliáceos que caracterizan los niveles precedentes del Solutrense superior, ello no implica que los foliáceos sean irrelevantes: su índice sigue siendo relativamente alto (Sala II, nivel XIV:
3\%; Sala I, niveles 3 a 5: 6\%) (Figs. 4 y 10). Y en este horizonte industrial siguen estando presentes todos los tipos morfológicos anteriores: las hojas de laurel, de sauce y las puntas de muesca.

$Y$ en cuanto a los microlitos retocados, poco numerosos en el Solutrense, se incrementan exponencialmente a partir del Magdaleniense inicial. Por otra parte, en los niveles del Solutrense final se constatan actividades de talla de foliáceos no sólo por la presencia de variados tipos de hojas de laurel y de otras específicamente solutrenses, sino también por la identificación de lasquitas de retoque plano entre los desechos de talla, posibilitada por el examen de los restos con la lupa binocular, lo que acredita que se han elaborado los foliáceos en el propio suelo de habitación de la cueva.

En el ámbito estratigráfico, en ocasiones los niveles del Solutrense final han sido interpretados de forma sesgada: se citan datos de las primeras excavaciones (CORCHÓN, 1981), que afectaron a una superficie muy reducida del Pasillo (Cata 1, de 1,5 × 1,5 m.). Y a la vez, se ignoran los sucesivos avances que han sido publicados, presentando resultados parciales de las excavaciones realizadas en el marco del Proyecto Nalón (1981-1999), en 
una superficie de $25 \mathrm{~m}^{2}$ que afecta a todas las unidades habitadas de la cavidad (las salas I y II, el contacto de la estratigrafía del Pasillo con la sala I, y el Corte exterior) (AURA et al, 2012). Y a la vez se han omitidos los resultados de las dataciones más fiables ( ${ }^{14} \mathrm{C}$ AMS) (CORCHÓN, 1994 y 1999-2000). Pero aún es más discutible el hecho de que, para sustentar la hipótesis de su relación con el Badeguliense, se hayan mezclado datos de las diversas unidades estratigráficas de la cueva, alterado la realidad sedimentológica del yacimiento (BOSSELIN y DJINDJIAN, 1999). En este modelo teórico, los niveles de Las Caldas han sido desprovistos de sus características esenciales, y su cronología real resulta alterada.

En consecuencia, no se sustenta en datos objetivos la atribución de los niveles 6 a 4 de la Sala I de Las Caldas al Badeguliense (BOSSELIN, 2000, AURA et al., 2012). Particularmente, el nivel 6 no debe ser incluido en el tramo Solutrense final ya que sus características tipológicas, los índices técnicos y los procedimientos de talla son similares a los del Solutrense superior de los niveles 7 e inferiores. Igualmente alejadas de la realidad estratigráfica y tecno-tipológica de los materiales de Las Caldas, se sitúan otras interpretaciones que ubican el paquete de niveles solutrenses 5 a 3 de la Sala I en el Magdaleniense arcaico, a causa de la presencia de raclettes (UTRILLA, 1996, 2004), lo que no se ajusta a los datos. Otra apreciación reciente (SAUVET et al., 2008) considera que los niveles 3 de la Sala I y el XIVc de la Sala II pertenecen al Magdaleniense arcaico/Badeguliense. Pero esta interpretación tampoco se sustenta en la realidad estratigráfica de Las Caldas, en cuyo registro no somos capaces de percibir diferencias de cultura material entre los niveles 5 a 3, y entre los diferentes tramos del nivel XIV (XIVa, XIVb y XIVc), a no ser algunos matices en el proceso de talla solutrense, que se han comentado.

En lo que se refiere a la secuencia del Magdaleniense inferior, no parece oportuno obviar los datos proporcionados por la única secuencia extensa conservada en el valle del Nalón, que ofrece 4 niveles homogéneos y sucesivos, todos ellos caracterizados por la abundancia de hojitas retocadas, triángulos, otros geométricos y algún microburil: los niveles XIII, XII inferior, XII y XI de Las Caldas. A la luz de los datos que arrojan las excavaciones extensas, y más allá de los debates abiertos sobre la existencia o no de una entidad badeguliense en la Región cantábrica, esta atribución y sobre todo la fracturación de una secuencia homogénea que desglosa de la misma a uno de sus niveles (SAUVET et al., 2008), no puede ser retenida. La ausencia de los marcadores atribuidos a aquella cultura se constata no sólo en la selección de las materias primas en los procesos de talla, sino en la irrelevante presencia de raclettes, que en ningún caso superan el $3 \%$ del total de útiles en estos niveles, y cuya morfología tampoco está plenamente definida. Igualmente alejadas de la realidad estratigráfica y tecno-tipológica de Las Caldas, se sitúan otras hipótesis que, a fortiori, incluyen los niveles 5 a 3 en el Magdaleniense arcaico, por la presencia de raclettes (UTRILLA, 1996, 2004).
Los datos analizados revelan que la estructura tecnotipológica del nivel 5 de Rascaño no guarda relación con ninguno de los conjuntos de Las Caldas; sólo se percibe alguna semejanza con la serie 8 a 10 de La Paloma (nivel seleccionado), pero estratigráficamente esta relación no puede ser sostenida.

Por otro lado, el nivel B de Entrefoces, como era de esperar dada su ubicación en el mismo valle, se asemeja al Magdaleniense inferior de Las Caldas. Pero la falta de un estudio riguroso y extenso de los niveles inferiores no permite verificar si existió o no una ocupación habitacional anterior, solutrense, aunque ya se ha señalado que existen indicios sólidos de la frecuentación de este yacimiento en época pre-magdaleniense, verosímilmente durante el Solutrense (Fig. 9).

El Magdaleniense inferior cantábrico, finalmente, representa una etapa de gran desarrollo tecnológico y diversidad en la cultura material. En la Cornisa Cantábrica se desarrollaron diversas modalidades regionales (o facies), que llegan a solaparse en el tiempo, y que en algunos casos parecen reflejar incipientes formas de vinculación territorial por parte de los diversos grupos sociales. Y a la vez, la larga duración de la secuencia, fehacientemente acreditada en el oriente de Asturias y en Cantabria -donde se suceden el Magdaleniense inferior y el Magdaleniense inferior tardío-, explica que éste último discurra paralelo en el tiempo con el Magdaleniense medio antiguo de tipo pirenaico desarrollado en el valle del Nalón.

Todo ello contrasta con la rareza de estas primeras industrias magdalenienses en los Pirineos. Es decir, los datos parecen dibujar un modelo opuesto al Badeguliense.

\section{5.- CONCLUSIONES}

Del estudio realizado se desprende que analizar las ocupaciones humanas como si se tratase de una fotografía instantánea, prescindiendo del contexto territorial y medioambiental en el que se desenvuelven, puede distorsionar la interpretación del registro estratigráfico. Un nivel aislado -y menos aún algunos útiles particulares, entresacados de contextos alejados donde, quizá, son representativos de unos grupos sociales concretos, por su peso específico en el conjunto del utillaje o su carácter novedoso-, no pueden ser indicativos de un proceso cultural. Las dificultades de interpretación, y la confusión introducida para explicar la transición del Solutrense final al Magdaleniense, con un modelo de intrusión de industrias regionales del sudoeste francés y la cuenca parisina, derivan en buena medida del hecho de que no existe un estudio diacrónico de las ocupaciones, en dicho periodo, de los grandes yacimientos de la Región cantábrica.

Desde una perspectiva tecnológica y de explotación de los recursos disponibles, se percibe que las variables que han intervenido tanto en la conceptualización de dicho horizonte como en la definición de las industrias son, en muchos casos, débiles. La gran variabilidad que 
muestran los registros transicionales entre el Solutrense superior y el Magdaleniense inicial cantábrico, es una característica que, en sí misma, invalida la existencia de un Badeguliense de tipo francés en la región, aunque se intenta soslayar esta realidad estratigráfica mediante un conjunto de facies atribuidas a un mismo grupo social.

La principal característica atribuida a estas industrias, que supuestamente interrumpen las tradiciones técnicas y tipológicas de los grupos solutrenses más recientes, es la rarificación de unas materias primas y el localismo en la selección de las mismas. Sin embargo, estos elementos forman parte sustancial de un proceso muy anterior, documentado en los registros, y en ocasiones en las secuencias estratigráficas extensas del Solutrense Superior y final, como La Riera, Cova Rosa, Cueto de Mina, los niveles 3 a 6 e inferiores de Las Caldas, El Mirón 117-119, Aiztbitarte IV, Arlanpe II, al menos con la misma evidencia que Rascaño 5, Llonín III, o Lloseta- El Rio. En concreto, los usos en el abastecimiento de las materias primas locales ha sido explicados por un cambio en los mecanismos de gestión territorial (RIOS et al. 2008), que se inicia en el LMG y se hace más patente en el centro-oeste de la Cornisa cantábrica, donde la cuarcita disponibles, de gran calidad y aptitud para la talla (por ejemplo, el tipo Barrios), es la materia prima lítica más utilizada en los procesos de talla analizados en los niveles que ocupan este segmento temporal. En suma, la gestión de los recursos abióticos es un proceso básicamente estable, aunque esté sujeto a los cambios graduales apuntados y que se perciben cuando se analizan los materiales desde una perspectiva diacrónica. Todo ello no parece guardar relación con los cambios radicales que se postulan, implícitos en un modelo de intrusión de industrias foráneas.

El utillaje lítico que se postula específico de estas industrias foráneas (el llamado "Badeguliense cantábrico"), incluye la desaparición de los tipos líticos propios del solutrense, como los foliáceos, aunque cuando están presentes se consideran elementos intrusivos que afloran desde niveles subyacentes, o bien no se valoran otros indicios de talla in situ de estos útiles como las lasquitas de retoque. Otras características serían el aumento de los útiles "arcaicos", también de las laminitas (lo que no es habitual en el Badeguliense francés), un equilibrio entre los índices de raspadores y buriles (BOSSELIN y DJINDJIAN, 1999), y la aparición de los útiles más característicos: las raclettes, los buriles transversales, junto a una peculiar técnica de grabado (VADILLO 2012, AURA et al., 2012, BOSSELIN y DJINDJIAN, 1999). Estas características no se encuentran en los niveles analizados.

En cuanto al ajuar óseo, se mencionan como elementos igualmente específicos de aquellas industrias, las azagayas de tipo Placard (Rascaño 5, Llonin III, Castillo 8, Lloseta, Cova Rosa, Cueto de Mina, Riera), y la técnica de pseudoexcisión, esta última considerada típica y que se postula exclusiva del Badeguliense
(DUARTE et al., 2014 y DUCASSE, 2013), lo que no concuerda con su presencia en niveles magdalenienses posteriores. Ambos tipos ya habían sido identificados en la colección de Rascaño 5 (UTRILLA, 2004), clasificando dicho nivel como Magdaleniense arcaico con características tecnológicas y tipológicas transicionales entre el Solutrense y el Magdaleniense. Pero concluir que la realización de surcos mediante una técnica que combina la incisión con la extracción (pseudoexcisión) es un elemento que identifica la presencia de un Badeguliense cantábrico, abre un nuevo debate acerca de la virtualidad de esta modalidad de incisión como indicadora de un cambio cultural en la Región cantábrica. Está probada su presencia en niveles como Rascaño 5, Llonin III, Cova Rosa y Aitzbitarte IV, pero se trata de elementos singulares -un total de 6 elementos en el registro cantábrico-, y se encuentra igualmente en el Magdaleniense medio de los mismos territorios.

En suma, se trata de un modelo de interpretación de niveles y secuencias de niveles tipificado a partir de sólo cuatro características, todas ellas con escaso peso estadístico en el conjunto de los utillajes comprendidos en el segmento temporal analizado. En este sentido, únicamente dos de los diez yacimientos citados en apoyo de la teoría badeguliense presentan el 100\% de las mencionadas características, consideradas diagnósticas. Cinco de ellos presentan tres de estas características, pero tampoco son estables ni homogéneos, sino que varían dependiendo del yacimiento: en dos casos ofrecen el 50\% de estas características, y otro muestra una sola de estas características, lo que difícilmente permite sostener su relación con este modelo.

En síntesis, cabe concluir que se trata de una argumentación débil para explicar una realidad tan diversa y difícil como es un tecnocomplejo industrial paleolítico.

En el caso del Mediterráneo, el valle del Ebro y la Meseta, el problema también parece ser de difícil solución, en muchos casos. Según esta interpretación (AURA et al., 2012): Gato 2 sólo presenta una de estas características; Maltravieso tan sólo presenta dos de estos rasgos; el Volcán del Faro ofrece tres de los citados caracteres, y únicamente El Parpalló mostraría las cuatro características. En suma, resulta una tarea ardua y compleja sostener un modelo de intrusión de industrias del sudoeste de Francia y la cuenca parisina a partir de unas bases metodológicamente frágiles.

\section{6.- AGRADECIMIENTOS}

Esta investigación ha sido realizada en el marco del Proyecto de Excelencia: Ocupación del territorio y actividad simbólica paleolítica en el centro de la Cornisa Cantábrica (27.000-12.000 B.P.). Los modelos de los valles del Nalón, Sella y Cares, Ref. HAR2013-41981-P, financiado por el Ministerio de Economía y Competitividad. IP: M $^{a}$ Soledad Corchón Rodríguez. 


\section{BIBLIOGRAFÍA}

ALLAIN, J. y FRITSCH R.

1967 Le Badegoulien de l'abri Fritsch aux Roches de PoulignySaint-Pierre (Indre). Bulletin de la Société Préhistorique française LXIV, 83-93.

ALLAIN J.

1989 La fin du Paléolithique supérieur en Région Centre", en RIGAUD J.-PH. (dir.): Le Magdalénien en Europe. La structuration du Magdalénien. 193-217. Actes du Colloque de Mayence, Sept. 1987. Liege : Etudes et Recherches Archéologiques de l'Université de Liège, 38.

ALTUNA, J.

1990 La cueva de Amalda (Zestoa, País Vasco): ocupaciones paleoliticas y postpaleolíticas. Eusko lkaskuntza. Donostia-San Sebastián.

\section{ALTUNA, J. y MARIUEZKURRENA, K.}

(ep) Macromamíferos de Las Caldas, en CORCHÓN M ${ }^{a}$ S. (coord.). La Cueva de Las Caldas: Ocupaciones solutrenses y magdalenienses en el valle del Nalón.

ÁLVAREZ, D. y ARRIZABALAGA, A.

2012 Aproximación al debate sobre la transición solutrensemagdaleniense en la cornisa cantábrica. Espacio tiempo y forma $5,171-181$.

ÁLVAREZ, E. y JÖRIS, O.

1998 El significado cronológico de algunas especies de fauna fría durante el Tardiglaciar en la Península Ibérica. Zephyrus $51,61-86$

AURA, E.

2007 Badegouliens et Magdaléniens du versant méditerranéen espagnol. Bulletin de la Société Préhistorique française 104 (4), 809-824.

AURA, J. E., TIFFANGOM, M., JORDÁ PARDO, J. F., DUARTE, E., FERNÁNDEZ DE LA VEGA, J., SANTAMARÍA, D., DE LA RASILLA, M., VADILLO, M. y PÉREZZ RIPOLL, M.

2012 The Solutrean-Magdalenian transition: A view from Iberia. Quatenary International 272-273, 1-13.

\section{BOSSELIN, B. y DJINDJIAN, F.}

1999 Une révision de la séquence de La Riera (Asturies) et la question du Badegoulien cantabrique. Bulletin de la Société Préhistorique Française 96, 153-173.

\section{BOSSELIN, B.}

2000 Le Badegoulien en Europe sud-occidentale faciès régionaux, paléonvironnement et filiations, en Paleolítico da Península Ibérica. Actas do $3^{\circ}$ Congresso de Arqueología Peninsular II. 363-387.

\section{CASTAÑOS, P}

1980 La Macrofauna de la Cueva de La Paloma", en HOYOS, M. et al (ed.). La Cueva de La Paloma. Soto de las Regueras (Asturias). 65-100. Excavaciones Arqueológicas en España 116. Madrid.

\section{CABRERA, V.}

1977 El yacimiento solutrense de Cueva Chufín (Riclones, Santander). Crónica del XIV Congreso Arqueológico Nacional, 157-164.

CABRERA, V., ALMAGRO, M. y BERNALDO DE QUIRÓS, F.

1976 Excavaciones en la Cueva de Chufin, Riclodes (Santander). Noticiario arqueológico hispánico 5, 107-112.

CORCHÓN, Ma S (dir.)

1981 Cueva de las Caldas. San Juan de Priorio (Oviedo). Excavaciones Arqueológicas en España 115. Madrid.

1992a Representaciones de fauna fría en el arte mueble de la cueva de Las Caldas (Asturias, España). Significación e implicaciones en el arte parietal. Zephyrus XLIV-XLV, 35-64.

1992b La cueva de Las Caldas (Priorio, oviedo). II Investigaciones efectuadas entre 1987 y 1990. Excavaciones Arqueológicas en Asturias 1987-1990, 34-47.

1993 El Magdaleniense con triángulos de Las Caldas (Asturias, España.) Nuevos datos para la definición del Magdaleniense Inferior Cantábrico. Zephyrus XLVI, 77-94.

1994 Arte mobiliar e Industria ósea solutrense en la Cornisa cantábrica. Vol. Monográfico: El Solutrense en la Península lbérica. Férvedes 1, 131-148.

1999a Solutrense y Magdaleniense del Oeste de la Cornisa Cantábrica: Dataciones14C (Calibradas) y marco cronológico. Zephyrus LII, 3-32.

1999b La cueva de Las Caldas (Priorio, Oviedo). IV. Excavaciones. 1995-1998. Excavaciones arqueológicas en Asturias 1995-98, 43-57.

2015 Los orígenes del arte parietal paleolítico en Asturias: el valle del Nalón como modelo", en BLAS. M.A. de (ed.). Expresión simbólica y territorial: Ios cursos fluviales y el arte paleolítico en Asturias. Real Instituto de Estudios Asturianos. Oviedo

\section{CORCHÓN, Ma S., TARRIÑO, A. y MARTÍNEZ, J.}

2009 Mobilité, territoires et relations culturelles au début du Magdalénien moyen cantabrique: nouvelles perspectives", en DJINDJIAN, F., KOZLOWSKI, J. y BICHO, N. (eds.). Le concept de territoires dans le Paléolithique supérieur européen. 217-230. Actes du XV Congrès de I'UISPP, Lisbonne, 2006. BAR International Series, 1938. Oxford.

CORCHÓN, Mª S., ORTEGA, P. y VICENTE, F.J.

2013 Cadenas operativas y suelos de ocupación. El nivel 9 de la cueva de Las Caldas (Asturias, España). Munibe Antroplogia-Arkeologia 64, 17-32.

CORCHÓN, Ma S., GARATE, D., RIVERO, O., VALLADAS, H., PONS-BRANCHU, E., MURELAGA, X., ORTEGA, P. y VICENTE, F.J.

2015 U-series and 14C datings for a newly discovered decorated area in the Palaeolithic cave of La Peña de Candamo (Asturies, Northern Spain). Journal Archaeological Science. Reports 3, 371-380.

CRETIN, C., FEULlO, O., FOURLOUBEY, Ch., LENOIR, M. y MORALA, A.

2007 Le Badegoulien du nord de l'Aquitaine : de nouveaux moyens de lectura. Bulletin de la Société Préhistorique française 104(4), 715-734. 


\section{CHEYNIER, A.}

1939 Le Magdalénien primitif de Badegoule: niveaux à raclettes. Bulletin de la Société Préhistorique française 36 (9): 354-396.

1949 Badegoule. Station solutréenne et protomagdalénienne. Archives de l'Institut de Paléontologie Humaine 23. París.

\section{DANZEGLOCKE, U., JÖRIS, O. y WENINGER, B.}

2012 CalPal-2007. Disponible en: http://www.calpal-online.de/. Accessed Junio de 2012.

DUARTE, E., RASILLA, M. de la y AURA, J.E.

2014 La técnica pseduexcisa en el Badeguliense/Magdaleniense arcaico de Asturias. Archivo de Prehsitoria Levantina XXX, 27-55.

\section{DUCASSE, $S$.}

2012 What is left of the Badegoulian "interlude"? New data on cultural evolution in southern France between 23,500 and 20,500 cal. BP. Quaternary International 272-273, 150-165.

2013 Badegoulien versus Magdalénien: I - Le Badegoulien recent quercinois : état de la recherche, rélexions et questionnements", en JARRY, M., BRUGAL, J.-PH. y FERRIER C. (dir.). Modalité d'occupation et exploitation des milieux au Paléolithique dans le Sud-Ouest de la France : l'exemple du Quercy Actes de la session C67, XVème Congrès mondial de l'UISPP, Lisbonne, sept. 2006. 361-378. PALEO, supplément 4.

\section{DUCASSE, S. y LANGLAIS, M.}

2007 Entre Badegoulien et Magdalénien, nos coeurs balancent... Approche critique des industries lithiques du Sud de la France et du Nord-Est espagnol entre 1900 et 16500 BP, Bulletin de la Société Préhistorique Française 104, 771-785.

DUCASSE, S., RENARD, C., ASTRUC, G., AVERBOUH. A., BRUXELLES, L. et al.

2012 De 20000 à 18000 BP en Quercy : apports de la séquence du Cuzoul de vers à la compréhensionde l'évolution des comportements socio-économiques entre Solutréen récent et Badegoulien, en CLOTTES, J., GlRAUD, J.-P. y CHALARD P. (dir.). Solutréen et Badegoulien au Cuzoul de Vers: Des chasseurs de rennes en Quercy, Liege. 459-471. ERAUL 131.

\section{DUCASSE, S., PÉTILLON, J-M. y RENARD, C.}

2014 Le cadre radiométriquede la séquence solutréo-badegoulienne du Cuzoul de Vers (Lot, France): lecture critique et compléments. Paleo 25, 37-58.

FORTEA, J., CORCHÓN, Ma S., GLEZ. MORALES, M., RODRÍGUEZ ASENSIO, A., HOYOS, M., LAVILLE, H., DUPRÉ, M. y FERNÁNDEZ, J.

1990 Travaux récents dans les vallées du Nalón et du Sella", en CLOTTES, J. (dir). L'Art des objets au Paléolitihique t. I, 219-244.

\section{GONZÁLEZ MORALES, M. R.}

1990 El abrigo de Entrefoces (1980-1983). Excavaciones Arqueológicas en Asturias 1983-1986, 29-36.

1992 Excavaciones en el abrigo de Entrefoces. Campaña de 1987 y 1989. Excavaciones Arqueológicas en Asturias 1987-1990, 49-52.

\section{GONZÁLEZ SAINZ, C}

1989 El Magdaleniense Superior-Final de la Región Cantábrica. Ed. Tantín. Santander.

\section{GONZÁLEZ SAINZ, C., RUIZ REDONDO, A. y GONZÁLEZ MO-} RALES M.R.

2013 Manifestaciones parietales paleolíticas de la cueva de El Molín y del abrigo de Entrefoces, (La Foz de Morcín, Asturias), en RASILLA M. de la (ed.). F. Javier Fortea Pérez, Universitatis Oventensis Magister (Estudios en homenaje). 375-399. Universidad de Oviedo y Mensula Ediciones. Oviedo.

HERNANDEZ-PACHECO, E.

1919 La caverna de la Peña de Candamo (Asturias). Comisión de Investigaciones Paleontológicas y Prehistóricas, memoria 24, Madrid.

HOYOS, M. et al (ed.)

1980 La Cueva de La Paloma. Soto de las Regueras (Asturias). Excavaciones Arqueológicas en España 116, Madrid.

HOYOS, M.

1995 Paleoclimatología del tardiglacial en la Cornisa Cantábrica basada en los resultados sedimentológicos de yacimientos arqueológicos kársticos, en MOURE, J.A. y GONZÁLEZ, C. (coord.). 15-76. El final del Paleolítico Cantábrico, Universidad de Cantabria. Santander.

JÖRIS, O. y WENINGER, B.

2000 Radiocarbon Calibration and the Absolute Chronology of the Late Glacial, en VALENTIN, B. et al (ed.). L'Europe septentrionale an Tardiglaciaire: confrontation des modèles régionaux de peuplement, Actes de la table-ronde internationale de Nemours. 19-54. Mémoires du Musée de préhistoire d'lle-de-France.

\section{LANGLAIS, M. y DUCASSE, S.}

2013 Badegoulien versus Magdalénien : II - le Magdalénien inférieur quercinois, en JARRY, M., BRUGAL, J.-PH. y FERRIER, C. (dir.). Modalité d'occupation et exploitation des milieux au Paléolithique dans le Sud-Ouest de la France: l'exemple du Quercy Actes de la sesión C67, XVème Congrès mondial de I'UISPP, Lisbonne, sept. 2006. 379-394. Paleo supplément 4.

RÍOS GARAIZAR J., IRIARTE, E., GARATE, D., GÓMEZ OLIVIENCIA, A. y SAN PEDRO, Z.

2008 Nuevos datos sobre la transición entre el Solutrense superior y el Magdaleniense inferior en la región cantábrica: la cueva de Arlanpe (Lemoa, Vizcaya). Sautuola XIV, 95-104.

RíOS GARAIZAR J., GARATE, D., GÓMEZ, A., ARCEDILLO, D., IRIARTE, E., GARCÍA MORENO, A, GARRIDO, D. y SAN PEDRO, Z.

2013 El final del solutrense en el oriente cantábrico a través de las ocupaciones de la cueva de Arlanpe (Lemoa, Vizcaya). Zephyrus LXXII, 15-38.

\section{SAUVET, G., FORTEA, J., FRITZ, C. y TOSELLO, G.}

2008 Crónica de los intercambios entre los grupos humanos paleolíticos. La contribución del arte para el período 20000 - 12000 años BP. Zephyrus LXI, 33-60. 
STRAUS, L. G.

1986 La Riera Cave: Stone Age hunter-gatherer adaptations in northern Spain. Arizona State Universty. Tempe.

2000 La grotte de la Riera (Asturies) et la question du Solutréen cantabrique (et Ibérique). Bulletin de la Société Préhistorique française, 97 (1) 129-132.

\section{STRAUS, L., GONZÁLEZ MORALES, M.R. y FONTES, L.M.}

2014 Initial Magdalenian artifact assemblages in El Mirón Cave (Ramales de La Victoria, Cantabria, Spain): a preliminary report. Zephyrus LXXIII, 45-65.

TROTIGNON, F., POULAIN, T. y LEROI-GOURHAN, A.

1984 Etudes sur l'abri Fritsch (Indre). Gallia préhistoire supplément 19.

\section{UTRILLA, P.}

1985 Reflexiones sobre el origen del Magdaleniense. Zephyrus XXXVII- XXXVIII 1984-85, 87-97.

1996 La sistematización del Magdaleniense Cantábrico: Una revisión histórica de los datos, en MOURE, A. (ed.). El Hombre fósil" 80 años después. 211-247. Servicio de Publicaciones de la Universidad de Cantabria. Santander.

2004 Evolución histórica de las sociedades cantábricas durante el Tardiglacial: El Magdaleniense inicial, inferior y medio (16.500-13.000 BP), en FANO, M. (ed.). Las Sociedades del Paleolítico en la Región Cantábrica. Kobie. Anejos 8, 243-274.
UTRILLA, P., DOMINGO, R., MONTES, L., MAZO, C., RODANÉS, J.M., BLASCO, F. y ALDAY, A.

2012 The Ebro Basin in NE Spain: A crossroads during the Magdalenian. Quaternary International 272-273, 88-10.

VADILLO, $\mathrm{M}$.

2012 Les indústries lítiques del Badegulià al Mediterrani peninsular. Estat actual de les investigacions. Archivo de Prehistoria Levantina XXIX, 81-98.

VACHER, G \& VIGNARD, E.

1964 Le Protomagdalénien I à raclettes des "Ronces" dans les Gros Monts de Nemours. Bulletin de la Société préhistorique française. Etudes et travaux 651 (1), 32-44.

VAQUERO, J.

2012 Revisión de los materiales líticos y gestión de una base de datos de clasificación tecnotipológica del yacimiento magdaleniense de Entrefoces (la Foz de Morcín, Asturias). Trabajo de Fin de Master. Universidad de Cantabria. Inédito.

VIGNARD, E.

1965 Le Badegoulien. Bulletin de la Société Préhistorique française, Présentations et comunications 62 (8), 262-263. 
